\title{
Control of flower development in Arabidopsis thaliana by APETALA1 and
}

\section{interacting genes}

\author{
John L. Bowman1, John Alvarez1, Detlef Weigel'2, Elliot M. Meyerowitz² and David R. Smyth ${ }^{1, *}$ \\ ${ }^{1}$ Department of Genetics and Developmental Biology, Monash University, Clayton, Victoria 3168, Australia \\ ${ }^{2}$ Division of Biology 156-29, California Institute of Technology, Pasadena, California 91125, USA \\ ${ }^{*}$ Author for correspondence
}

\section{SUMMARY}

Mutations in the APETALA1 gene disturb two phases of flower development, flower meristem specification and floral organ specification. These effects become manifest as a partial conversion of flowers into inflorescence shoots and a disruption of sepal and petal development. We describe the changes in an allelic series of nine apetalal mutants and show that the two functions of APETALA1 are separable. We have also studied the interaction between $A P E T A L A 1$ and other floral genes by examining the phenotypes of multiply mutant plants and by in situ hybridization using probes for several floral control genes. The results suggest that the products of $A P E T A L A 1$ and another gene, $L E A F Y$, are required to ensure that primordia arising on the flanks of the inflorescence apex adopt a floral fate, as opposed to becoming an inflorescence shoot. APETALA1 and
$L E A F Y$ have distinct as well as overlapping functions and they appear to reinforce each other's action. $C A U$ LIFLOWER is a newly discovered gene which positively regulates both $A P E T A L A 1$ and $L E A F Y$ expression. All functions of CAULIFLOWER are redundant with those of APETALA1. APETALA2 also has an early function in reinforcing the action of $A P E T A L A 1$ and $L E A F Y$, especially if the activity of either is compromised by mutation. After the identity of a flower primordium is specified, APETALA1 interacts with APETALA2 in controlling the development of the outer two whorls of floral organs.

Key words: Arabidopsis, flower development, apetalal, inflorescence, meristem, cauliflower

\section{INTRODUCTION}

Most angiosperm species are induced to flower in response to environmental conditions such as day length and temperature, and internal cues including age. Following germination, the shoot meristem produces a series of leaf meristems on its flanks. However, once floral induction has occurred flower meristems arise instead. These in turn produce a determinate number of floral organ primordia, which develop individually into sepals, petals, stamens or carpels. Thus, flower formation can be thought of as a series of distinct developmental steps - floral induction, the formation of flower primordia and the production of floral organs. Mutations disrupting each of the steps have been isolated in a variety of species, suggesting that a genetic hierarchy directs the flowering process (for review see Weigel and Meyerowitz, 1993).

Recently, studies of two distantly related dicotyledons, Arabidopsis thaliana and Antirrhinum majus, have shed light on some of the molecular genetic mechanisms underlying the flowering process. For example, the specification of floral organ identity depends on the products of at least three classes of homeotic genes, acting alone and in combination (Bowman et al., 1989, 1991; Carpenter and Coen,
1990; Schwarz-Sommer et al., 1990). Several of these genes are transcription factors whose conserved DNA-binding domain has been named the MADS box (Schwarz-Sommer et al., 1990; Coen and Meyerowitz, 1991).

Earlier-acting genes controlling the identity of floral meristems have also been characterized. Flower meristems are derived from the flanks of the indeterminate inflorescence meristem in both Arabidopsis and Antirrhinum. Two of the factors that determine that these meristematic cells will develop as flowers are known. In Arabidopsis, they are the products of the $L E A F Y$ gene (Weigel et al., 1992) and the APETALAl gene (Mandel et al., 1992). When inactivated by mutation, the flanking primordia develop into structures combining the properties of flowers and inflorescence shoots in both leafy mutants (Schultz and Haughn, 1991; Huala and Sussex, 1992; Weigel et al., 1992) and, in different ways, in apetalal mutants (Irish and Sussex, 1990). In Antirrhinum, the homologue of the Arabidopsis LEAFY gene is FLORICAULA (Coen et al., 1990) and that of the APETALAl gene is SQUAMOSA (Huijser et al., 1992). The latter pair contain MADS box domains.

An allelic series of strong, intermediate and weak leafy mutants has recently been characterized, presumably containing progressively higher levels of $L E A F Y$ activity. This 
series has been useful in deducing the wild-type $L E A F Y$ function (Huala and Sussex, 1992; Weigel et al., 1992). Further, the $L E A F Y$ gene product seems to interact with that of APETALAI as the phenotype of the apetalal leafy double mutant deviates more severely from wild type than do the phenotypes of either single mutant (Huala and Sussex, 1992; Weigel et al., 1992).

Here we describe the phenotypes of an allelic series of nine apetalal mutants and compare their morphology and development. We have also examined interactions between apetalal mutants and those of five other floral control genes. One of these is a new gene, CAULIFLOWER, which greatly enhances the apl mutant phenotype when in homozygous recessive form. The results extend those of an earlier study of the apetalal-1 mutant (Irish and Sussex, 1990) and provide insights into the various roles APETALA1 plays in controlling the identity of flower primordia and of floral organs that arise on them.

\section{MATERIALS AND METHODS}

\section{Origin of mutant alleles}

The origins of the nine mutant ap1 alleles studied are summarized in Table 1.

The cauliflower-1 allele was identified as an enhancer of ap1-1 in the $\mathrm{F}_{2}$ of a cross between an ap1-1 plant of Landsberg erecta background and a wild-type Wassilewskija (Ws) ecotype plant (Feldmann and Marks, 1987). Selfing of plants homozygous for ap 1-1 and heterozygous for cal-1 resulted in a segregation of 498 ap1-1 to 175 apl-1 cal-1 plants in the next generation. The enhanced phenotype was identified in five out of five $\mathrm{F}_{2}$ families, indicating that it is homozygous in the Ws background. Two lines of evidence suggest that the apparently recessive cal-1 allele is specific to Ws. Firstly, no enhancement of the ap1-1 mutant phenotype was observed after crosses to different ecotypes (Columbia, Niederzenz, Bensheim and Kiruna, a late flowering ecotype). Secondly, mutant apl alleles isolated in four different ecotypes, Landsberg erecta, Columbia, Nossen and either Estland or Limburg (Table 1), display the non-enhanced phenotype. For phenotypic analyses, the recessive cauliflower allele was backcrossed into the Landsberg erecta apl-1 background five times. The cal locus is on chromosome 1 in the vicinity of ga4 and dis2.

Mutants of other genes used in this study have been described previously (Table 2).

\section{Genetic and phenotypic analyses}

Plants were raised in a mixture of equal parts of perlite and a commercial seed-raising mix and irrigated with nutrient solution. Except where noted, phenotypic analyses were done on plants grown in a greenhouse maintained at close to $25^{\circ} \mathrm{C}$ under constant illumination with fluorescent lights (cool white) at approximately $130 \mu \mathrm{E} \mathrm{m}^{-2} \mathrm{sec}^{-1}$ in addition to natural daylight. For other temperatures, phenotypic analyses were performed on plants grown under continuous fluorescent lighting at $15 \pm 1^{\circ} \mathrm{C}$ or $30 \pm 1^{\circ} \mathrm{C}$.

All double mutants segregated close to the expected ratio of $1: 15$ in $\mathrm{F}_{2}$ families. For ap1-1 ap2-2, ap 1-4 lfy-5 and ap1-5 ap2-1, seeds were harvested from individual apl or ap $2 \mathrm{~F}_{2}$ plants, and the novel double mutant phenotype was observed in a $1: 3$ ratio in the $\mathrm{F}_{3}$ generation. The apl-1 cal-1 lfy-6 and apl-1 cal-1 tfl-2 triple mutants were identified by harvesting seed from individual apl-1 cal-1 $\mathrm{F}_{2}$ plants and observing the novel phenotype segregating $1: 3$ in the $F_{3}$

Table 1. Origin of mutant ap1 alleles

\begin{tabular}{|c|c|c|c|c|c|}
\hline Allele & Isolation no. & Effect & Ecotype & Mutagen & Origin \\
\hline 1 & - & strong & Landsberg $e r$ & EMS* & M. Koornneef \\
\hline 2 & S1504 & intermediate-strong & Landsberg er & EMS & present study \\
\hline 3 & $\mathrm{~S} 1350$ & weak & Landsberg $e r$ & EMS & present study \\
\hline 4 & S1735 & intermediate & Landsberg $e r$ & EMS & present study \\
\hline 5 & $\mathrm{~S} 1732$ & weak & Landsberg $e r$ & EMS & present study \\
\hline 6 & $\mathrm{La} 77313 / 2$ & intermediate & Landsberg $e r$ & not recorded & P. Maher (ex M. Koornneef) \\
\hline 7 & S2723 & strong & Columbia & EMS & present study \\
\hline 8 & axillaris & intermediate & Estland or Limburg & not recorded & A. D. McKelvie (ex M. Koornneef) \\
\hline 9 & LC500 & strong & Nossen & EMS & L. Comai \\
\hline
\end{tabular}

*ethylmethane sulfonate.

The ap1-1 and ap 1-3 mutations are the result of splice site acceptor changes at the third and fifth introns, respectively, and ap 1-2 is a glycine to aspartate change at a conserved residue in the MADS box (Mandel et al., 1992).

Table 2. Properties of loci tested for interactions with ap1 mutations

\begin{tabular}{|c|c|c|c|c|}
\hline Locus & Summary of mutant phenotype & $\begin{array}{c}\text { Allele } \\
\text { used }\end{array}$ & Effect & Reference \\
\hline leafy (lfy) & flower meristems partially converted to inflorescence meristems & $\begin{array}{l}5 \\
6\end{array}$ & $\begin{array}{l}\text { weak } \\
\text { strong }\end{array}$ & $\begin{array}{c}\text { Weigel et al. (1992) } \\
,,\end{array}$ \\
\hline cauliflower (cal) & $\begin{array}{l}\text { no effect alone, interacts with apl mutants to fully convert flower } \\
\text { meristems to inflorescence meristems }\end{array}$ & 1 & $?$ & present study \\
\hline terminal flower $(t f)$ & apex of inflorescence meristems converted to floral meristems & 2 & strong & Alvarez et al. (1992) \\
\hline apetala2 (ap2) & $\begin{array}{l}\text { homeotic conversion of outer two whorls of floral organs } \\
\text { sepals converted to leaves, petals partially converted to stamens } \\
\text { sepals converted to carpels, petals mostly absent } \\
\text { sepals converted to carpels, petals mostly absent }\end{array}$ & $\begin{array}{l}1 \\
2 \\
9\end{array}$ & $\begin{array}{l}\text { weak } \\
\text { strong } \\
\text { intermediate }\end{array}$ & $\begin{array}{c}\text { Bowman et al. (1989) } \\
\text { Bowman et al. (1991) } \\
,\end{array}$ \\
\hline agamous (ag) & $\begin{array}{l}\text { homeotic conversion of inner two whorls of floral organs } \\
\text { stamens converted to petals, carpels converted to another flower } \\
\text {," }\end{array}$ & $\begin{array}{l}1 \\
2 \\
3\end{array}$ & $\begin{array}{l}\text { strong } \\
\text { strong } \\
\text { strong }\end{array}$ & $\begin{array}{l}\text { Bowman et al. (1989) } \\
\text { Yanofsky et al. (1990) } \\
\text { Bowman et al. (1991) }\end{array}$ \\
\hline
\end{tabular}


generation. The heterozygous effect of cal-1 in the apl-1 background was shown by crossing ap $1-1$ cal-1 plants with ap $1-1$ plants and observing a phenotype intermediate to that of the two parents in the $\mathrm{F}_{1}$ plants. The heterozygous effect of cal-1 in the apl-5 and ap 1-1 tfl-2 backgrounds was shown similarly. The triple mutant ap1-1 ap2-2 ag-1 was identified as follows. A novel phenotype was recorded in the $\mathrm{F}_{2}$ of a cross between an ap1-1 plant and a plant homozygous for both ap2-2 and pi-1 and heterozygous for $a g-1$. Seeds were collected from individual $\mathrm{F}_{2}$ ap $1-1$ plants. Some of the $\mathrm{F}_{3}$ families segregated the novel phenotype at the ratio of about 1:7. Each of these families homozygous for ap 1-1 segregated ap22 and $a g-1$ but not necessarily $p i-1$. This segregation ratio (ap2 and $a g$ are linked and show about $25 \%$ recombination) and the segregating phenotypes indicate that the novel phenotype corresponds to the ap1-1 ap2-2 ag-1 triple mutant. That no different phenotype was noted in those families also segregating pi-l suggests that the ap 1-1 ap2-2 ag-1 pi-1 quadruple mutant is indistinguishable from the ap1-1 ap2-2 ag-1 triple mutant.

For phenotypic analyses, usually the first fifteen structures produced by the primary inflorescence meristem after cauline leaf production were examined.

Scanning electron microscopy (SEM) was performed as described in Alvarez et al. (1992) except that an accelerating voltage of $20 \mathrm{kV}$ was used and images were recorded on either Kodak Plus-X Pan 220 professional film or Ilford FP4 film.

\section{In situ hybridization}

Fixation of tissue, sectioning, hybridization and washes were carried out as described by Drews et al. (1991). Briefly, inflorescences were fixed for 3 hours in 3.7\% formaldehyde, 5\% acetic acid and $50 \%$ ethanol. Fixed tissue was dehydrated with ethanol, cleared with Histo-Clear (National Diagnostics) and embedded in paraffin (Paraplast Plus). Embedded tissue was sliced into serial 8 $\mu \mathrm{m}$ sections with a Reichert-Jung 2040 microtome and attached to microscope slides coated with poly-L-lysine (Sigma). $\left.{ }^{35} \mathrm{~S}\right] \mathrm{UTP}$ probes were generated by run-off transcription with T3, T7 or SP6 RNA polymerase (Promega). Probes were synthesized from templates described by Weigel et al. (1992) and Mandel et al. (1992). In the case of $A P 1$, probes were synthesized from a region of the gene that did not cross-hybridize with any other cloned genes (Mandel et al., 1992). Slides were dipped in nuclear emulsion, exposed for from one to two weeks, developed for 2.5 minutes in Kodak D19 and stained with toluidine blue.

\section{RESULTS}

The apical meristem of Arabidopsis thaliana generates leaves until the plant becomes florally induced. Induction occurs relatively rapidly under the influence of long days or much later under short-day conditions (Napp-Zinn, 1985). It results in the apical meristem generating the primary inflorescence shoot and bractless flowers are now produced on its flanks instead of leaves (Fig. 1). The leaves and flowers arise in a continuous phyllotactic spiral, and the number of flowers produced is indeterminate. The plant bolts soon after the first flower primordia develop due to increased internode elongation between several of the later-formed leaves (cauline leaves) and between flowers. A cluster of earlierformed rosette leaves remains at the base of the stem. Each of the cauline leaves contains an axillary inflorescence meristem that reiterates the development of the primary inflorescence. The inflorescence is a raceme with the development of individual flowers proceeding acropetally (from basal to apical positions; Müller, 1961).

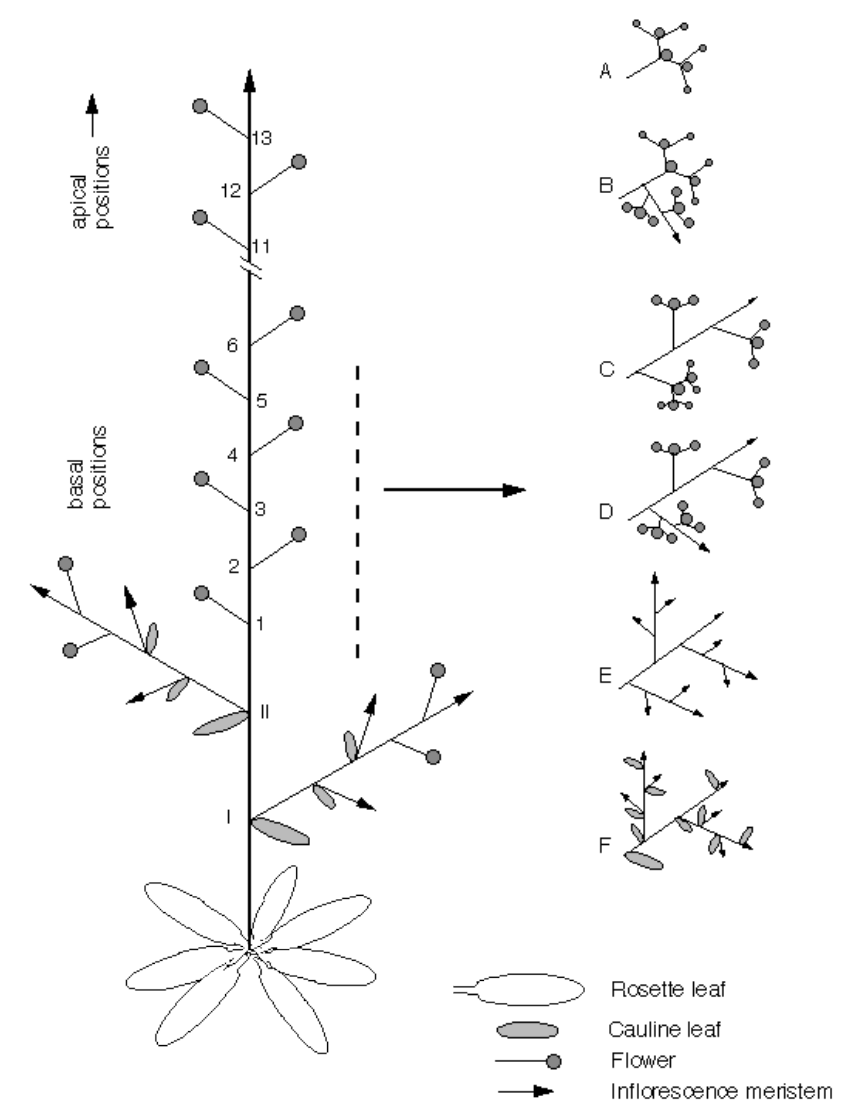

Fig. 1. Schematic representation of a wild-type Arabidopsis thaliana plant (left) and some of the alterations in apetala1 mutants (right). The roman numbers refer to the positions of the cauline leaves and the arabic numbers refer to the positions of flowers. Floral positions 1-5 are referred to as basal and positions 11 and above are referred to as apical. In all cases, the inflorescences arising in the axils of cauline leaves (at I and II) develop in the same manner as the main inflorescence. A-F represent structures found in the basal flower positions of apetalal mutants or in double and triple mutant combinations involving apetala1 alleles. (A) Determinate branched structure, common in strong apetalal mutants. (B) Pedicellar inflorescence on a determinate branched structure, present in strong apetalal mutants and in apetala1 plants heterozygous for cauliflower-1. (C) Second order inflorescence (what would normally be a flower meristem behaves instead as an inflorescence meristem), present in strong apetalal mutants. (D) Second order inflorescence with a third order inflorescence, present in strong apetalal mutants. (E) Positions normally occupied by floral meristems occupied by inflorescence meristems; occurs in apetala 1-1 cauliflower-1 plants. (F) Positions normally occupied by flowers occupied by leafy shoots; occurs in apetalal leafy- 6 and apetalal leafy- 6 cauliflower-1 plants.

Arabidopsis flowers are composed of four concentric whorls of organs, with four sepals in the outermost whorl, four petals in the second whorl, six stamens in the third whorl (four medial and two lateral) and two fused carpels occupying the center of the flower (Fig. 2B; Müller, 1961; Hill and Lord, 1989; Smyth et al., 1990). Their early development has been described in detail and divided into twelve stages (Smyth et al., 1990; Fig. 2A). 

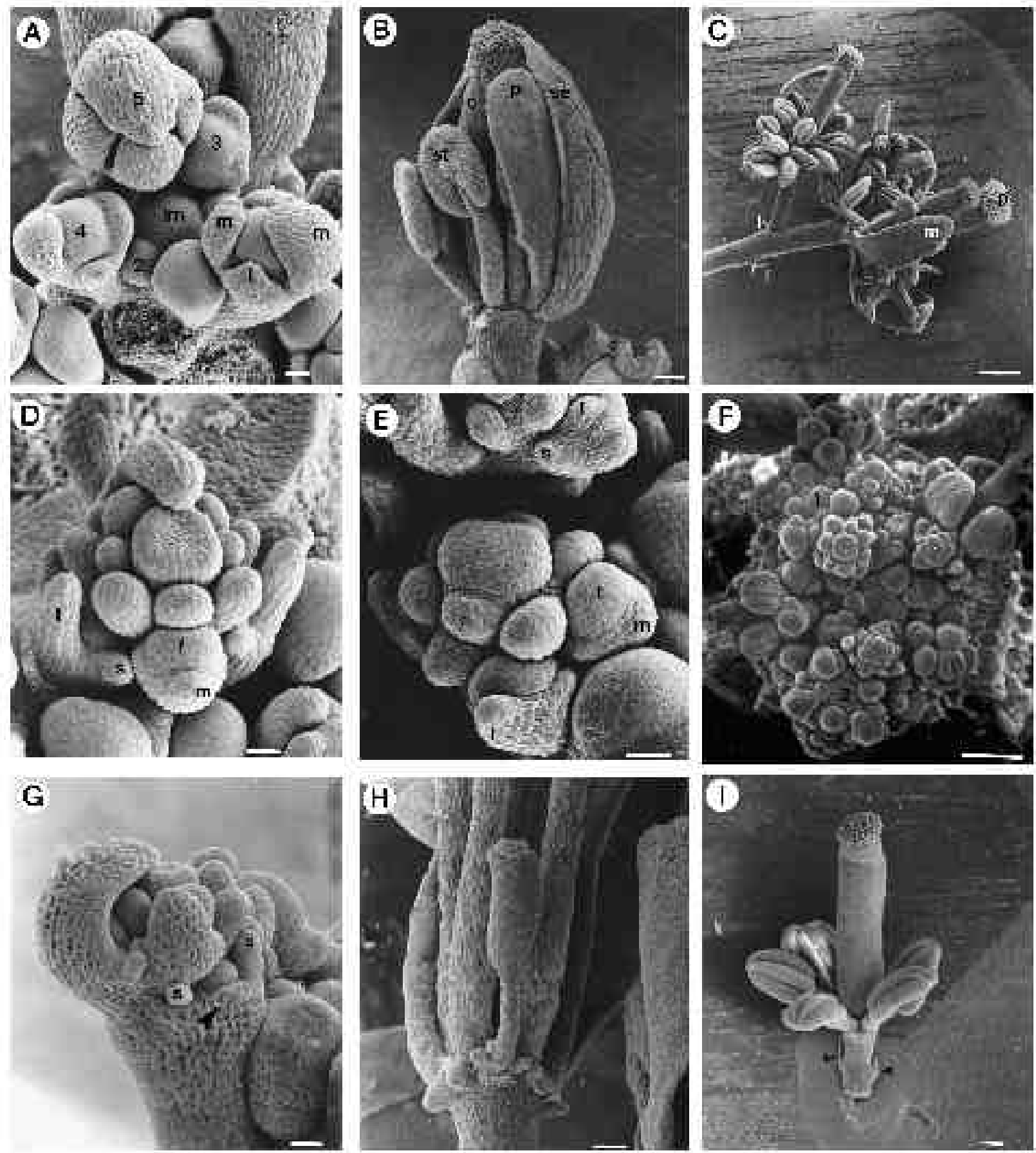

Fig. 2. SEMs of wild-type (A,B) and apetalal (C-I) inflorescences and flowers. Adaxial and abaxial refer to positions relative to the inflorescence meristem, while lateral and medial refer to positions of floral organs relative to the floral meristem. Stages of flower development are according to Smyth et al. (1990). (A) Vertical view of wild-type inflorescence meristem (im), with flower buds at stages 2-5 indicated. Note lateral (l) and medial (m) sepals arise at nearly the same level on the pedicel. (B) Nearly mature wild-type flower (stage 12) partly dissected showing sepals (se), petals (p), stamens (st) and carpels (c). (C) Determinate branched structure characteristic of the basal floral positions of apl-1 inflorescences (Fig. 1A). In this case, the structure consists of five axillary flowers and a central primary (p) flower. Note internode elongation between the lateral (l) and medial (m) first whorl organs of the primary flower. (D-E) Stage 6 ap 1-1 flowers. The lateral (1) first whorl organs arise lower on the pedicel than the medial (m) first whorl organs. The axillary floral buds (f) arise directly from the first whorl organs. Stipules (s) often flank the first whorl organs. The pattern of the second and third whorl organ primordia is abnormal. (F) Developing ap 1-1 inflorescence. The two basal positions normally occupied by flowers are occupied by second order inflorescence meristems $(1,2)$. (G) A leaf-like primordium (arrowhead) flanked by stipules (s) and with an associated axillary meristem is developing in a lateral position from the pedicel of this ap 1-7 flower. $(\mathrm{H})$ A much reduced axillary flower of an ap 1-1/ap1-5 trans-heterozygous plant, consisting of only an abnormal, two-carpelled gynoecium. (I) An apical apl-1 flower in which the first whorl organs have failed to develop fully and the aborted primordia of the two lateral organs are visible (arrowheads). No second whorl organs are present. Bar, $20 \mu \mathrm{m}$ in A,D,E,G; $100 \mu \mathrm{m}$ in B,F,H,I; $300 \mu \mathrm{m}$ in C. 
We have characterized nine recessive mutant apl alleles (Table 1), one of which, apl-1, has been described in detail previously (Irish and Sussex, 1990). The mutant alleles can be arranged into a phenotypic series (strong, intermediate and weak) based both on the extent of inflorescence-like character exhibited by apl flowers and the severity of alterations in floral organ development. These two aspects will be discussed separately.

\section{ap1 mutations cause partial transformations of flowers into inflorescences}

The production of leaves is not altered in apl mutants. However, those meristems that would give rise to a single flower in wild type instead often give rise to a determinate, branched structure comprised of several individual flowers (Figs 1A, 2C). These structures consist of a central 'primary' flower with the extra flowers usually arising slightly later in the axils of the first whorl organs of the primary flower. In turn these secondary flowers may also have flowers arising in the axils of their first whorl organs, and so on such that tertiary and quaternary flowers may be formed. The overall result is a complex branched structure. In some cases, axillary flowers may not be subtended by a fully developed organ (Fig. 2C). However, close inspection reveals that there is usually an aborted organ primordium with flanking stipules (Fig. 3K).

In apl mutant plants, the total number of flowers in the branched structures varies acropetally (from bottom to top of the inflorescence shoot) and with growth temperature (Table 3). The most basal positions in relatively strong mutants (alleles 1, 9, 7 and 2) may have more than twenty branched flowers arising from the position a single flower would occupy in wild type, while the more apical positions may be occupied by a single flower. Similarly, growth at lower temperatures $\left(15^{\circ} \mathrm{C}\right)$ results in more flowers per branch while growth at $30^{\circ} \mathrm{C}$ results in less. In flowers of intermediate apl alleles (4, 6 and 8), the determinate structures are seldom composed of more than eight individual flowers, while in weak apl alleles (5 and 3) no axillary flowers were observed at $25^{\circ} \mathrm{C}$ (Table 3 ).

Ectopic inflorescences may sometimes develop directly on the pedicels of apl flowers. They arise below the first whorl organs of the primary flowers of the determinate branched structures (Fig. 1B). The ectopic structures are usually not associated with any subtending organ or aborted primordia, although occasionally they arise from the axil of a cauline leaf-like organ. In strong alleles, these 'pedicellar inflorescences' are relatively common. For example, 39 were observed on 20 apl-1 plants and 18 on 6 ap 1-7 plants.

In stronger alleles the main 'flower' meristem itself may sometimes behave as a full inflorescence meristem, producing an indeterminate number of flowers in a phyllotactic spiral (Figs 1C, 2F). We term this a second order inflorescence meristem (the first order is the normal apical inflorescence meristem). Even third order inflorescence meristems (Fig. 1D) may sometimes develop. These higher order apices develop in a manner that is indistinguishable from that of the apical inflorescence meristem (Fig. 2F), suggesting that the transformation of flower to inflorescence meristem is complete. Such conversions are almost always restricted to the most basal positions of the main inflorescence stem. At $25^{\circ} \mathrm{C}$, there are only one or two per plant (if any) for strong and intermediate alleles, and none at all for weak alleles (Table 3). However, the number varies markedly with temperature. For example, apl-1 plants grown at $15^{\circ} \mathrm{C}$ had an average of 11 secondary inflorescences in the first 15 'flower' positions, while at $30^{\circ} \mathrm{C}$ only one was seen on 15 apl-1 plants (Table 3).

Thus strong and intermediate mutant apl alleles show partial, and occasionally complete, conversions of flowers to inflorescences, especially at basal positions.

Table 3. Mean number of flowers* per pedicel/peduncle $\dagger$ in ap1 plants

\begin{tabular}{|c|c|c|c|c|c|c|c|c|c|c|c|c|}
\hline & \multicolumn{11}{|c|}{ Allele: } & \multirow{4}{*}{$\begin{array}{l}\text { wild } \\
\text { type }\end{array}$} \\
\hline & \multicolumn{5}{|c|}{ strong } & \multicolumn{4}{|c|}{ intermediate } & \multicolumn{2}{|c|}{ weak } & \\
\hline & \multicolumn{3}{|c|}{1} & \multirow[t]{2}{*}{9} & \multirow[t]{2}{*}{7} & \multirow[t]{2}{*}{2} & \multirow[t]{2}{*}{6} & \multirow[t]{2}{*}{4} & \multirow[t]{2}{*}{8} & \multirow[t]{2}{*}{5} & \multirow[t]{2}{*}{3} & \\
\hline & $15^{\circ} \mathrm{C}$ & $25^{\circ} \mathrm{C}$ & $30^{\circ} \mathrm{C}$ & & & & & & & & & \\
\hline flowers $1-5 \ddagger$ & ND & 9.1 & 2.7 & 4.3 & 4.4 & 4.6 & 3.3 & 3.6 & 1.8 & 1.0 & 1.0 & 1.0 \\
\hline flowers 6-10 & ND & 3.7 & 1.3 & 3.7 & 1.9 & 2.8 & 2.1 & 2.2 & 1.5 & 1.0 & 1.0 & 1.0 \\
\hline flowers $11-15$ & ND & 2.1 & ND & 3.3 & 1.6 & 1.8 & 1.8 & 1.8 & 1.3 & 1.0 & 1.0 & 1.0 \\
\hline $\begin{array}{l}\text { second order } \\
\quad \text { inflorescences } \$\end{array}$ & 210 & 5 & 1 & 24 & 1 & 12 & 1 & 1 & 0 & 0 & 0 & 0 \\
\hline no. of plants scored & 19 & 16 & 15 & 15 & 15 & 15 & 15 & 15 & 15 & 15 & 15 & 15 \\
\hline $\begin{array}{l}\text { All plants were gr } \\
* \text { A flower in this s } \\
\text { in each of the axils o } \\
\text { are counted as flowe } \\
\text { †Since the determ } \\
\text { stem for these struct } \\
\text { †Flowers } 1-5 \text { refer } \\
\text { Flowers 6-10 and } 11 \\
\text { \$This represents tl } \\
\text { inflorescence meriste } \\
\text { classes are included }\end{array}$ & $\begin{array}{l}\text { in at } 25^{\circ} \\
\text { se is de } \\
\text { ts four f } \\
\text { only wh } \\
\text { ate inflo } \\
\text { s. } \\
\text { the firs } \\
5 \text { refer t } \\
\text { total nu } \\
\text { (Fig. 1C }\end{array}$ & $\begin{array}{l}\text { unless } \\
\text { hed as a } \\
\text { t whorl } \\
\text { they h } \\
\text { scence- } \\
\text { five det } \\
\text { the corr } \\
\text { ber of t } \\
\text { Pedice }\end{array}$ & $\begin{array}{l}\text { therwis } \\
\text { loral-lil } \\
\text { organs, } \\
\text { ve a ter } \\
\text { ke struc } \\
\text { rminate } \\
\text { spondin } \\
\text { nes a m } \\
\text { lar (Fig }\end{array}$ & $\begin{array}{l}\text { ted. ND } \\
\text { tructure } \\
\text { number } \\
\text { al gyno } \\
\text { es are ne } \\
\text { Ictures }( \\
\text { ore api } \\
\text { tem tha }\end{array}$ & $\begin{array}{l}\text { eans no } \\
\text { is term } \\
\text { lowers } \\
\text { m. } \\
\text { er true f } \\
\text { 1A) pr } \\
\text { structur } \\
\text { wild-ty } \\
\text { and hig }\end{array}$ & $\begin{array}{l}\text { termine } \\
\text { ted by a } \\
\text { pedicel } \\
\text { ers nor } \\
\text { iced by } \\
\text { vould b } \\
\text { order ir }\end{array}$ & $\begin{array}{l}\text { nccium. } \\
\text { ncle we } \\
\text { nfloresc } \\
\text { pical in } \\
\text { ral mer } \\
\text { scence }\end{array}$ & $\begin{array}{l}\text { examp } \\
\text { be five } \\
\text { es, the } \\
\text { scence } \\
\mathrm{m} \text {, beh } \\
\text { istems }\end{array}$ & $\begin{array}{l}\text { if a priı } \\
\text { he axill } \\
\text { n pedic } \\
\text { ristem } \\
\text { d instea } \\
1 \mathrm{D}, \mathrm{E}\end{array}$ & $\begin{array}{l}\text { flower } \\
\text { lowers } \\
\text { duncle } \\
\text { wing ce } \\
\text { an inde } \\
\text { not inc }\end{array}$ & $\begin{array}{l}\text { flower } \\
\text { ten inc } \\
\text { d to } \mathrm{de} \\
\text { leaf } \mathrm{p} \\
\text { nate se } \\
\text { None }\end{array}$ & $\begin{array}{l}\text { structur } \\
\text { lete, and } \\
\text { the flora } \\
\text { ction. } \\
\text { order } \\
\text { hese }\end{array}$ \\
\hline
\end{tabular}


Table 4. First whorl organs of ap1 flowers

\begin{tabular}{|c|c|c|c|c|c|c|c|}
\hline & \multicolumn{6}{|c|}{ Allele: } & \multirow{3}{*}{$\begin{array}{l}\text { wild } \\
\text { type }\end{array}$} \\
\hline & \multirow{2}{*}{$\begin{array}{c}\text { strong } \\
1\end{array}$} & \multicolumn{3}{|c|}{ intermediate } & \multicolumn{2}{|c|}{ weak } & \\
\hline & & 2 & 6 & 4 & 5 & 3 & \\
\hline \multicolumn{8}{|c|}{ Flowers $1-5$, medial positions } \\
\hline sepals & 0 & 0 & 0 & 0 & 0 & 0 & 40 \\
\hline petaloid leaves & 0 & 0 & 0 & 0 & 22 & 21 & 0 \\
\hline leaves & 0 & 34 & 28 & 38 & 11 & 7 & 0 \\
\hline bracts & 16 & 6 & 12 & 2 & 6 & 7 & 0 \\
\hline carpelloid bracts & 0 & 0 & 0 & 0 & 1 & 2 & 0 \\
\hline staminoid bracts & 0 & 0 & 0 & 0 & 0 & 2 & 0 \\
\hline filamentous organs & 1 & 0 & 0 & 0 & 0 & 1 & 0 \\
\hline absent & 23 & 0 & 0 & 0 & 0 & 0 & 0 \\
\hline \multicolumn{8}{|c|}{ Flowers 1-5, lateral positions } \\
\hline sepals & 0 & 0 & 0 & 0 & 0 & 0 & 40 \\
\hline petaloid leaves & 0 & 0 & 0 & 1 & 0 & 0 & 0 \\
\hline leaves & 0 & 22 & 9 & 36 & 17 & 23 & 0 \\
\hline bracts & 14 & 4 & 5 & 0 & 19 & 6 & 0 \\
\hline carpelloid bracts & 0 & 0 & 0 & 0 & 0 & 0 & 0 \\
\hline staminoid bracts & 0 & 1 & 0 & 0 & 0 & 0 & 0 \\
\hline filamentous organs & 5 & 2 & 0 & 1 & 1 & 7 & 0 \\
\hline absent & 21 & 11 & 26 & 2 & 3 & 4 & 0 \\
\hline \multicolumn{8}{|c|}{ Flowers $11-15$, medial positions } \\
\hline sepals & 0 & 0 & 0 & 0 & 0 & 0 & 40 \\
\hline petaloid leaves & 0 & 0 & 0 & 0 & 0 & 6 & 0 \\
\hline leaves & 0 & 0 & 0 & 0 & 0 & 0 & 0 \\
\hline bracts & 23 & 37 & 31 & 40 & 0 & 3 & 0 \\
\hline carpelloid bracts & 0 & 0 & 4 & 0 & 19 & 9 & 0 \\
\hline staminoid bracts & 0 & 0 & 1 & 0 & 20 & 22 & 0 \\
\hline filamentous organs & 1 & 2 & 0 & 0 & 0 & 0 & 0 \\
\hline absent & 16 & 1 & 0 & 0 & 1 & 0 & 0 \\
\hline \multicolumn{8}{|c|}{ Flowers 11-15, lateral positions } \\
\hline sepals & 0 & 0 & 0 & 0 & 0 & 0 & 40 \\
\hline petaloid leaves & 0 & 0 & 0 & 0 & 0 & 0 & 0 \\
\hline leaves & 0 & 0 & 0 & 0 & 0 & 0 & 0 \\
\hline bracts & 7 & 12 & 10 & 24 & 21 & 24 & 0 \\
\hline carpelloid bracts & 0 & 0 & 0 & 0 & 0 & 0 & 0 \\
\hline staminoid bracts & 0 & 0 & 0 & 0 & 0 & 0 & 0 \\
\hline filamentous organs & 6 & 1 & 0 & 2 & 2 & 3 & 0 \\
\hline absent & 27 & 27 & 26 & 14 & 17 & 13 & 0 \\
\hline
\end{tabular}

Four plants grown at $25^{\circ} \mathrm{C}$ were scored for each mutant.

\section{ap1 mutations alter the development of floral organs}

The presence, identity and position of the outer two whorls of organs are usually altered in apl mutants (Figs 2, 3; Tables 4, 5).

\section{First whorl effects}

Strong alleles. The first whorl organs display features not found in either floral or vegetative organs of wild-type plants. They have been referred to as bract-like since they resemble the bracts that subtend flowers of many other species (Irish and Sussex, 1990). The shape of the organs is neither sepal-like nor leaf-like, being elongate and rather pointed and lacking a defined petiole (Fig. 3A). They do have some leaf-like properties including epidermal cells resembling those of leaves, stipules and late senescence, while sepal-like characteristics include elongate cells on their outer surface and the absence of stellate trichomes. Other first whorl positions of strong mutants are not occupied by fully developed organs but aborted primordia,
Fig. 3. SEMs of floral organs of strong, intermediate and weak apetalal mutants. (A,B,I) strong ap 1-1 mutant; $(\mathrm{J}, \mathrm{K})$ intermediate ap1-2 and apl-4 mutants; (C-H,L,M) weak apl-3 and ap 1-5 mutants. (A) Bract-like (b) organ in the first whorl position of a primary apl-1 flower. A tertiary flower (arrow) can be seen in the axil of the first whorl organ of the secondary flower. (B) Stage 5 ap 1-1 flower. The four first whorl organs are in cruciform phyllotaxy, but the lateral (l) first whorl organs are lower on the pedicel than the medial $(\mathrm{m})$ first whorl organs. The pattern of the third whorl organ primordia is abnormal. (C) Mosaic first whorl organ from an ap 1-3 flower, consisting of distinct sectors of petaloid (p) tissue and tissue that appears intermediate between sepal and leaf-like (se) tissue. (D) Mature apical apl-5 flower. A carpelloid bract-like organ (b) is seen in the first whorl as well as two petal-stamen mosaic organs (ps) in the second whorl. (E) Stage 5 ap 1-3 flower. The first whorl organs are narrow and, unlike wild type, fail to enclose the bud. (F) Young ap 1-3 inflorescence. (G) Petal (p) and stamen (st) mosaic organ from the second whorl of an ap1-5 flower. (H) Close up of (F) showing the distinct sectors of petal (above) and stamen (below) tissue. (I) Nearly wild-type petals occasionally develop in second whorl positions of ap 1-1 flowers. (J) Stage 5 ap 1-2 flower. The lateral (1) first whorl organ is flanked by stipules and is lower on the pedicel the medial (m) first whorl organs. The first whorl organs of basal ap1-2 flowers are generally leaf-like. One of the visible second whorl organ primordia (arrowhead) is much larger than the other and will most likely also develop into a leaf-like organ. (K) apl-4 flower. The axillary flower bud (f) is not subtended by a fully developed lateral first whorl organ but rather an aborted primordium (1) flanked by stipules (s). A second whorl position is occupied by a filamentous structure (arrowhead). (L) Apical ap 1-5 flower at stage 5. One of the two visible second whorl primordia (2) is close to the same level as the lateral third whorl primordium (3). Thus the distinction between second and third whorl positions is sometimes ambiguous. (M) Petal-stamen mosaic organ in an ap 1-5 flower. In this case, it appears that a lateral third whorl primordium may have congenitally fused with a second whorl primordium, resulting in the development of a hybrid organ with petaloid (p) and staminoid (st) tissue. Second (2) and third (3) whorl stamens are also visible. Bar, $20 \mu \mathrm{m}$ in B,E,F,H,J-L; $40 \mu \mathrm{m}$ in $\mathrm{C} ; 100 \mu \mathrm{m}$ in $\mathrm{A}, \mathrm{D}, \mathrm{G}, \mathrm{I}, \mathrm{M}$.

often flanked by stipules, are frequently present (Fig. 2I, Table 4). In the more acropetal flowers, organs often fail to fully develop in all four first whorl positions (Fig. 2I).

Observations of developing flowers show that the four first whorl primordia are usually produced in a whorled, cruciform pattern (Fig. 3B). However, the pattern is often slightly twisted and, unlike wild type, the lateral organ primordia are usually initiated much lower on the receptacle than the medial primordia. In addition, later internode elongation between organs, especially those of the first whorl, results in their marked spatial separation (Fig. 2C).

In the more acropetal flowers (positions 20 and higher, Fig. 1) of strong alleles grown at $25^{\circ} \mathrm{C}$, the medial first whorl organs develop carpelloid characteristics such as stigmatic papillae at their tips and rudimentary ovules along their margins. This is accentuated when apl-1 plants are grown at $30^{\circ} \mathrm{C}$ where the medial first whorl organs develop as solitary carpels. The lateral organs are less affected in each case.

Intermediate alleles. The first whorl organs of basal flowers in apl alleles 2, 4 and 6 more closely resemble leaves (Table 4). They are triangular in shape, flanked by stipules (Fig. 3K), and have stellate trichomes present on 

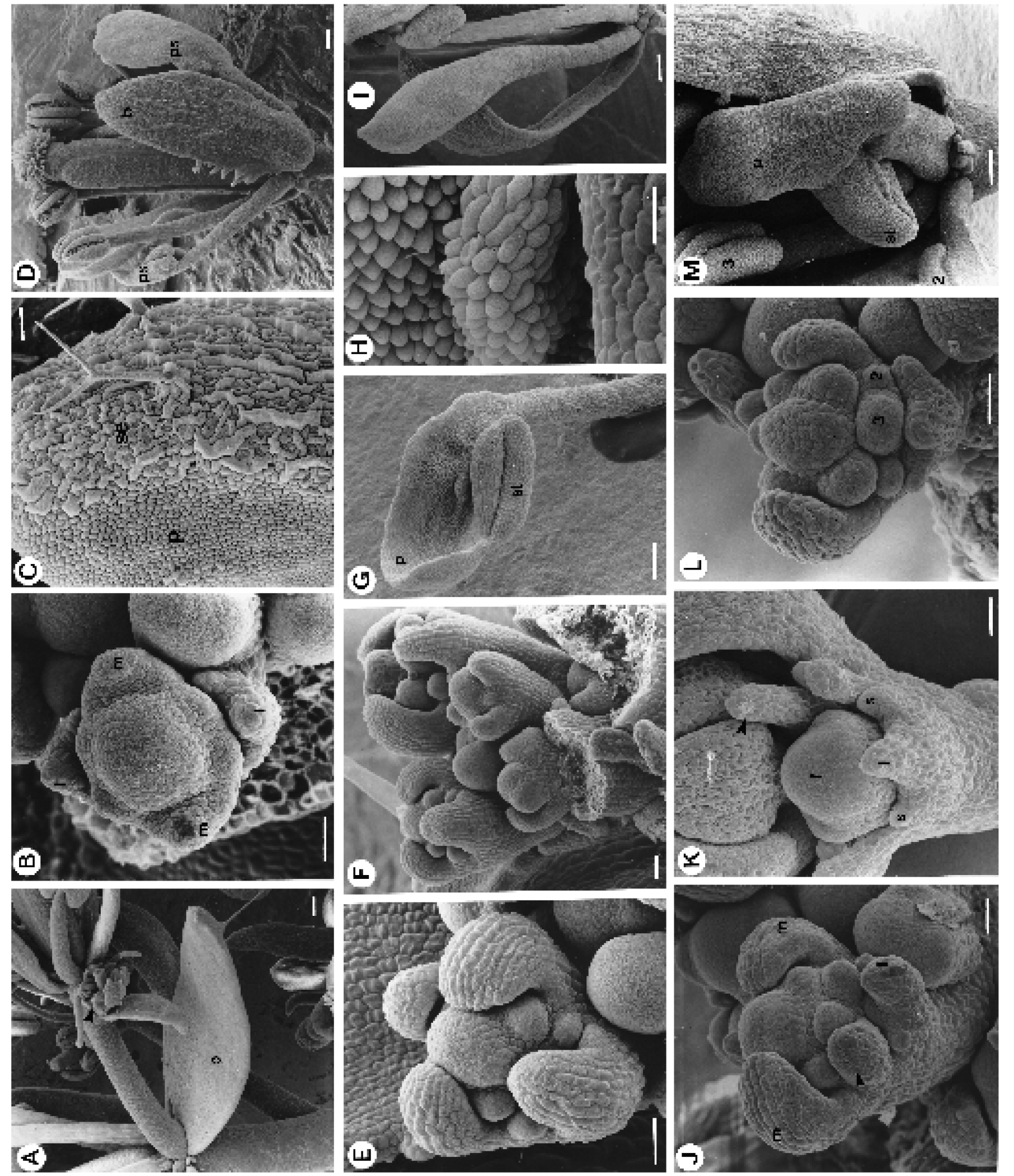
Table 5. Second whorl organs of ap1 flowers

\begin{tabular}{|c|c|c|c|c|c|c|c|}
\hline & \multicolumn{6}{|c|}{ Allele: } & \multirow{3}{*}{$\begin{array}{l}\text { wild } \\
\text { typ }\end{array}$} \\
\hline & \multirow{2}{*}{$\begin{array}{c}\text { strong } \\
1\end{array}$} & \multicolumn{3}{|c|}{ intermediate } & \multicolumn{2}{|c|}{ weak } & \\
\hline & & 2 & 6 & 4 & 5 & 3 & \\
\hline \multicolumn{8}{|l|}{ Flowers 1-5 } \\
\hline petals & 0 & 0 & 21 & 39 & 65 & 54 & 80 \\
\hline petaloid stamens & 4 & 0 & 19 & 0 & 10 & 6 & 0 \\
\hline stamens & 0 & 15 & 3 & 0 & 0 & 1 & 0 \\
\hline filamentous organs & 3 & 5 & 1 & 6 & 0 & 1 & 0 \\
\hline petaloid leaves & 2 & 1 & 7 & 22 & 0 & 0 & 0 \\
\hline staminoid leaves & 0 & 6 & 0 & 0 & 0 & 0 & 0 \\
\hline leaves & 0 & 16 & 0 & 1 & 0 & 0 & 0 \\
\hline absent & 71 & 37 & 29 & 12 & 5 & 18 & 0 \\
\hline \multicolumn{8}{|l|}{ Flowers 11-15 } \\
\hline petals & 0 & 0 & 0 & 6 & 1 & 14 & 80 \\
\hline petaloid stamens & 0 & 2 & 19 & 1 & 10 & 16 & 0 \\
\hline stamens & 1 & 10 & 7 & 2 & 15 & 16 & 0 \\
\hline filamentous organs & 0 & 6 & 0 & 40 & 0 & 5 & 0 \\
\hline petaloid leaves & 0 & 0 & 0 & 3 & 0 & 0 & 0 \\
\hline staminoid leaves & 0 & 1 & 4 & 1 & 0 & 0 & 0 \\
\hline leaves & 0 & 3 & 2 & 2 & 0 & 0 & 0 \\
\hline absent & 79 & 58 & 48 & 25 & 54 & 29 & 0 \\
\hline
\end{tabular}

Four plants grown at $25^{\circ} \mathrm{C}$ were scored for each mutant.

both adaxial and abaxial surfaces. They become more bractlike acropetally (Table 4), and in flowers above about the tenth to fifteenth position, they usually resemble those of basal flowers of strong mutants.

Weak alleles. There is a marked difference between the morphology of the medial and lateral first whorl organs in ap 1-5 and ap 1-3. On basal flowers the medial organs superficially resemble wild-type sepals but are usually mosaics of central phylloid tissue and marginal petaloid tissue (Fig. $3 \mathrm{C})$. The boundaries between the two types of tissue are usually sharp. On more apical flowers, the medial organs become leaf-like (flowers 6 to 10) and then bract-like (flowers 11 to 15 and above, Table 4), although they are often mosaics including sectors of bract-like, carpel and stamen tissue (Fig. 3D). By contrast, the lateral first whorl organs are more often bract-like, are not usually mosaics and are often absent in the more apical positions (Table 4).

All first whorl organ primordia of weak alleles arise in a cruciform pattern, but they are narrower and more pointed than wild-type sepal primordia and the lateral primordia may be lower on the receptacle compared to wild type (Figs 3E, $3 \mathrm{~F})$. There is little or no aberrant internode elongation between the lateral and medial first whorl organs.

\section{Second whorl effects}

Strong alleles. The most common case for ap 1-1, ap 1-7 and apl-9 flowers is that no organs occupy the second whorl positions (for ap1-1 data see Table 5; Irish and Sussex, 1990). This is due to the failure to initiate any second whorl organ primordia (Fig. 2D,E). However, a small fraction of the second whorl positions are occupied by either nearly wild-type petals, morphologically wild-type stamens, or mosaic organs with distinct sectors of petal and either stamen or bract-like tissue. Although no petals were observed in the sample of plants scored for Table 5, nearwild-type petals are sometimes seen (e.g. Fig. 3I).

Intermediate alleles. Second whorl organs are often
Fig. 4. SEMs of apetalal cauliflower inflorescences. (A) Wildtype apex showing inflorescence meristem (im) and developing stage 1-3 flower buds. (B) ap 1-1 cal-1 inflorescence apex at a similar age as that of A. Primordia produced by the apical inflorescence meristem (im) are also behaving as inflorescence meristems rather than flower meristems. (C) apl-1 cal-1 inflorescence apex at a slightly older stage than B. Note the second order inflorescence meristems (2) are morphologically indistinguishable from that of the apical inflorescence meristem (im). (D) Side view of a young ap1-1 cal-1 inflorescence. (E) Side view of a much older ap1-1 cal-1 inflorescence. (F) Close up of the structure occupying the most basal floral position in E. This structure developed from a meristem (a second order inflorescence meristem) that in wild type would have given rise to a single flower. (G) Close up of the structure produced by a third order inflorescence in F. Fourth (4) and higher order inflorescence meristems are visible. $(\mathrm{H})$ Apical inflorescence meristem (im) of $\mathrm{E}$ with young second and third order inflorescence meristems visible. (I) Differentiating apl-1 cal-1 inflorescence. The flowers resemble apical ap 1-1 flowers. (J) ap 1-1 cal-1 inflorescence apex of a plant grown at $16^{\circ} \mathrm{C}$. Note the numerous developing cauline leaves (cl) and cauline leaf primordia (arrowhead). (K) Flower homozygous for ap 1-1 and heterozygous for cal-1. A pedicellar inflorescence (see Fig. 1B) is visible (arrowhead). (L) ap1-1 cal-1 $t f l$-2 inflorescence. No supernumerary inflorescence meristems are evident and the apical inflorescence meristem terminates in a flower (t). Bar, $20 \mu \mathrm{m}$ in A,B; $40 \mu \mathrm{m}$ in C,D,H; $100 \mu \mathrm{m}$ in F,G,I,$\mathrm{L} ; 500 \mu \mathrm{m}$ in $\mathrm{E}$.

absent, especially in apical positions. When present, their structures differ markedly between the three intermediate alleles scored (Table 5). For ap1-2, stamens and leaf-like organs are often present, especially in basal flowers. The leaves closely resemble those of the first whorl both in mature morphology and in ontogeny. Their early growth is rapid compared with normal second whorl petal primordia (Fig. 3J). By contrast, apl-4 plants often have petals and petaloid leaves in early flowers, later changing to filamentous organs (Fig. 3K; Table 5). In the second whorl of apl6 , petals and petaloid stamens predominate (Table 5).

When organs with properties of two organ types develop, they may appear either as distinct mosaics or as blends. Distinct sectors occur in organs composed of petal and stamen tissue, whereas epidermal cells in petal/leaf organs seem to combine the properties of petals (domed-shaped with radial ridges) and leaves (rectangular with some stomata present).

Weak alleles. In basal flowers, the second whorl is most frequently occupied by morphologically wild-type petals as in wild type (Table 5). However, in the more apical flowers, such organs are often absent. When present, they are either mosaic organs consisting of distinct stamen and petal tissue (Fig. 3G,H) or morphologically wild-type stamens.

\section{Third and fourth whorl effects}

apl mutations have only minor effects on the third whorl. Even in strong alleles there are often six stamens present. However, the mean number per flower is slightly reduced (5.2 in ap 1-1 compared with 5.9 in wild type), and the reduction is more marked in apical positions and at higher temperatures (a mean of near 4 for ap 1-1 plants raised at $30^{\circ} \mathrm{C}$ ) Observations on developing ap 1 flowers show that the boundary between the second and third whorl primordia is 

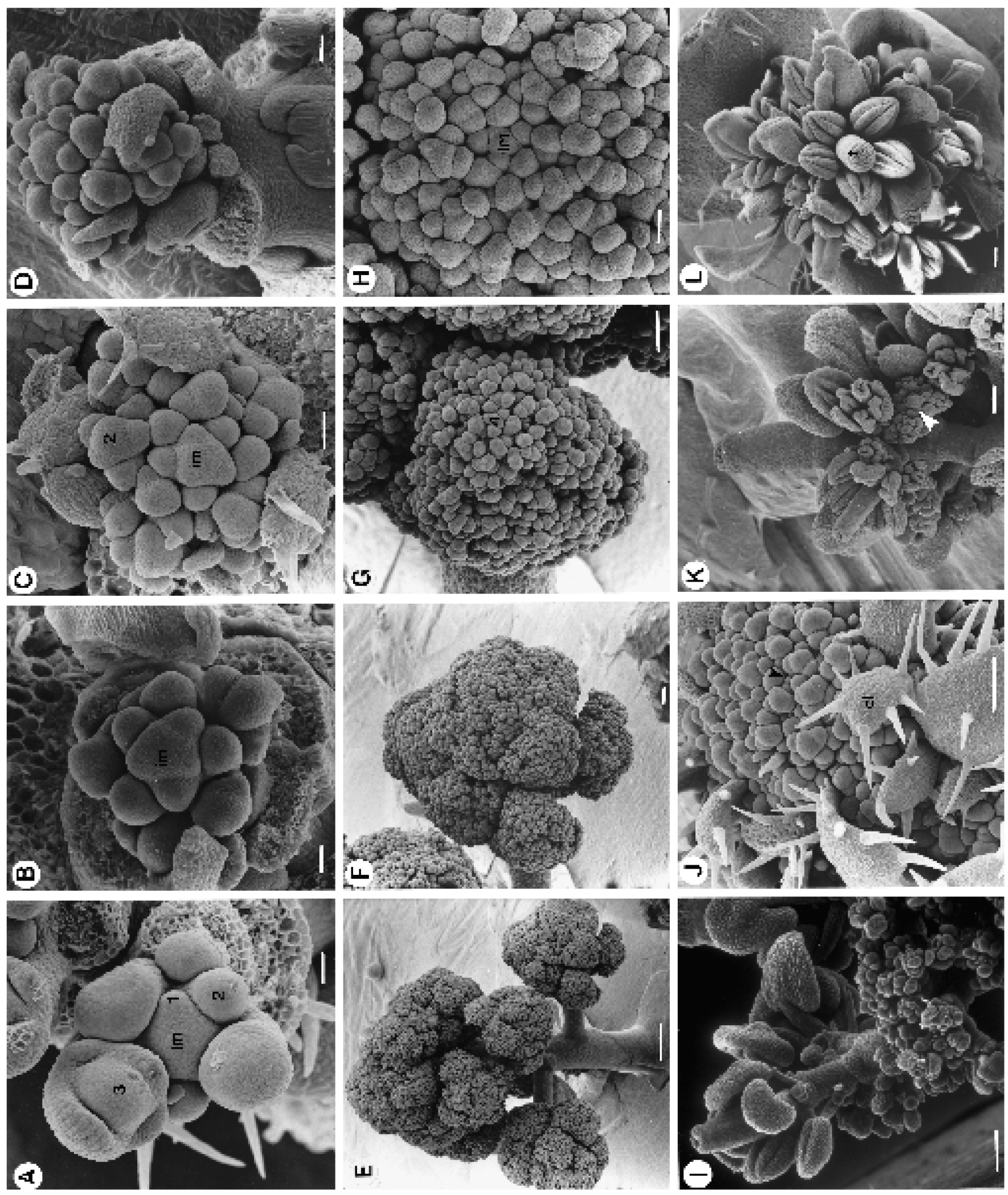
often distorted (Fig. 3L), especially when fewer than six third whorl primordia develop. In these cases, it was sometimes difficult to assign an organ to the second or third whorl. Relevant to this, second and third whorl organs are occasionally fused ( 2 cases in 60 apl-3 flowers; 1 case in 60 ap 1-5 flowers, e.g. Fig. 3M), and mosaic organs consisting of petal and stamen tissue may arise from intermediate positions.

Finally, the fourth whorl gynoecium of apl flowers is usually normal although occasionally the two carpels are not completely fused, primarily in flowers arising higher on the main stem.

It is worth pointing out that the structures of second and higher order flowers within determinate branched flowers (Fig. 1A) are at least as severely affected as the primary flower and often more so. In the extreme, they may consist of a solitary two-carpelled gynoecium (Fig. $2 \mathrm{H}$ ).

In conclusion, study of floral organs in nine mutant apl alleles has revealed the following generalizations. (i) The outer two whorls of organs are preferentially affected. (ii) The lateral first whorl organs tend to be bract-like or absent. (iii) The medial first whorl organs are highly variable and can range from being bract-like to leaf-like to carpelloid. (iv) Second whorl organs tend to be absent in strong mutants, staminoid in intermediate mutants and petaloid in weak mutants. (v) Mosaic organs tend to arise in the medial first whorl and all second whorl positions, especially in the weaker alleles. (vi) Later-produced apical flowers are more severely affected than earlier produced basal flowers. (vii) Higher temperatures result in a strengthening of the mutant phenotype for each of the alleles.

\section{cauliflower enhances the ap1 phenotype}

An apparently recessive allele of the CAULIFLOWER $(C A L)$ locus, cal-1, significantly enhances the apl phenotype (see Materials and Methods for the origin of cal1). In ap 1-1 cal-1 double mutants, each meristem that in wild type would give rise to a single flower, consistently behaves instead as an inflorescence meristem. These meristems arise in a phyllotactic spiral on the flanks of the main apex in positions where flowers would normally arise (Fig. 4B). In turn these second order inflorescence meristems immediately produce further meristems in a phyllotactic spiral that also behave as inflorescence meristems, i. e. third order inflorescence meristems (Figs 1E, 4B-D). This process may be repeated several times resulting in the production of fourth, fifth and higher order inflorescence meristems (Fig. 4E-H). The transformed inflorescence meristems are indistinguishable from the primary apical inflorescence meristem.

After a large number of undifferentiated meristems has developed, individual flowers may eventually differentiate from a few of the last-formed meristems on any one branch (Fig. 4I). They may arise from high order meristems on early formed branches or from second or third order meristems on later formed branches. The meristems develop into individual flowers that have a phenotype like that of apical apl-1 flowers.

The number of orders of inflorescence meristem that are produced varies acropetally and with environmental conditions. When grown at $25^{\circ} \mathrm{C}$, the basal positions of apl-1
Fig. 5. Expression patterns of APETALAl in apl cal and $t f$ plants. In situ hybridization of a $A P 1$ anti-mRNA probe with longitudinal sections $(8 \mu \mathrm{m})$ through wild-type (A,B), ap 1-1 cal-1 (C-F) and $t f l-2$ (G-J) inflorescence apices. Each section was photographed in two ways: bright field (A,C,E,G,I) and dark field (B,D,F,H,J). (A,B) Wild type. A high level of APl signal is associated with stage 1-2 flowers, as seen in the two stage 2 flowers (2), but no signal is observed in the inflorescence meristem (im). From stage 3 , signal becomes restricted to the cells that will give rise to the outer two whorls (arrowheads on the stage 4 flower), whereas no signal is seen in tissue that will give rise to whorls three and four. Expression is maintained in the sepals (se) and petals (pe), at least until the flower opens. In addition, a high signal is associated with the pedicel (pd) throughout flower development. (C,D) Young ap1-1 cal-1 inflorescence apex grown at $25^{\circ} \mathrm{C}$ (similar to that in Fig. 4C). A low but significant signal is seen in some of the meristems (arrowhead) produced by the apical inflorescence meristem (im). (E,F) Inflorescence of an older ap 1-1 cal-1 plant grown at $25^{\circ} \mathrm{C}$ (similar to that in Fig. $4 \mathrm{~F}$ ). A level of $A P 1$ signal comparable to that of wild-type stage 1-2 flowers can be seen in many of the supernumerary meristems (arrowheads). However, no signal is detected in the older inflorescence meristems such as the second order meristem indicated (2). In addition, signal is detected in the pedicels/peduncles of the proliferating meristems (pd). This signal appears stronger in the pedicels of the higher order meristems. $(\mathrm{G}, \mathrm{H})$ Young $t f l-2$ inflorescence apex. Ectopic $A P 1$ signal is present in the meristems $(\mathrm{m})$ in the axils of the cauline leaves (1). These meristems give rise to inflorescences in wild type, but are transformed into flower meristems in $t f l-2$ plants. The primary inflorescence meristem (im) also expresses APl around its flanks (arrowheads), presumably in first whorl floral organ primordia of a developing terminal flower. (I, J) Older $t f l-2$ inflorescence apex. APl signal can be seen in the first whorl sepal of the developing terminal flower (se). In addition, ectopic API signal is seen in the inflorescence stem (is) below the terminal flower. This region acts as the pedicel of the terminal flower. Bars, $200 \mu \mathrm{m}$. Each autoradiograph is shown at the same magnification as its corresponding bright-field micrograph.

cal-1 plants may have up to ninth order inflorescence meristems, while the more apical positions may have only second order inflorescence meristems. When grown under unfavorable conditions ( such as $30^{\circ} \mathrm{C}$ ) the basal positions may have only second or third order inflorescence meristems, whereas in the apical positions flowers develop without any proliferation of higher order inflorescence meristems. Perhaps the most striking phenotype occurs when apl-1 cal-1 plants are grown at $15^{\circ} \mathrm{C}$. In this case no differentiation of flowers was observed after four months, by which time twelfth order inflorescence meristems were present. Additionally, such plants produce cauline leaves at many positions within the second, third and higher order inflorescence meristems (Fig. 4J).

ap 1-1 plants heterozygous for cal-1 also display a slightly enhanced mutant phenotype. Such plants have an increased number of pedicellar inflorescences (Figs 1B, 4K; 87 pedicellar inflorescences were scored on 11 plants grown at $25^{\circ} \mathrm{C}$ ). In addition, the frequency of second and third order inflorescence meristems (Fig. 1D) developing in the basal positions is increased. Thus the cal-1 allele is not completely recessive, but weakly semi-dominant.

The cal-1 allele also modifies the phenotype of weak apl alleles. For example, the phenotype of ap 1-5 cal-1 plants is enhanced so that it now resembles that of the strongest 

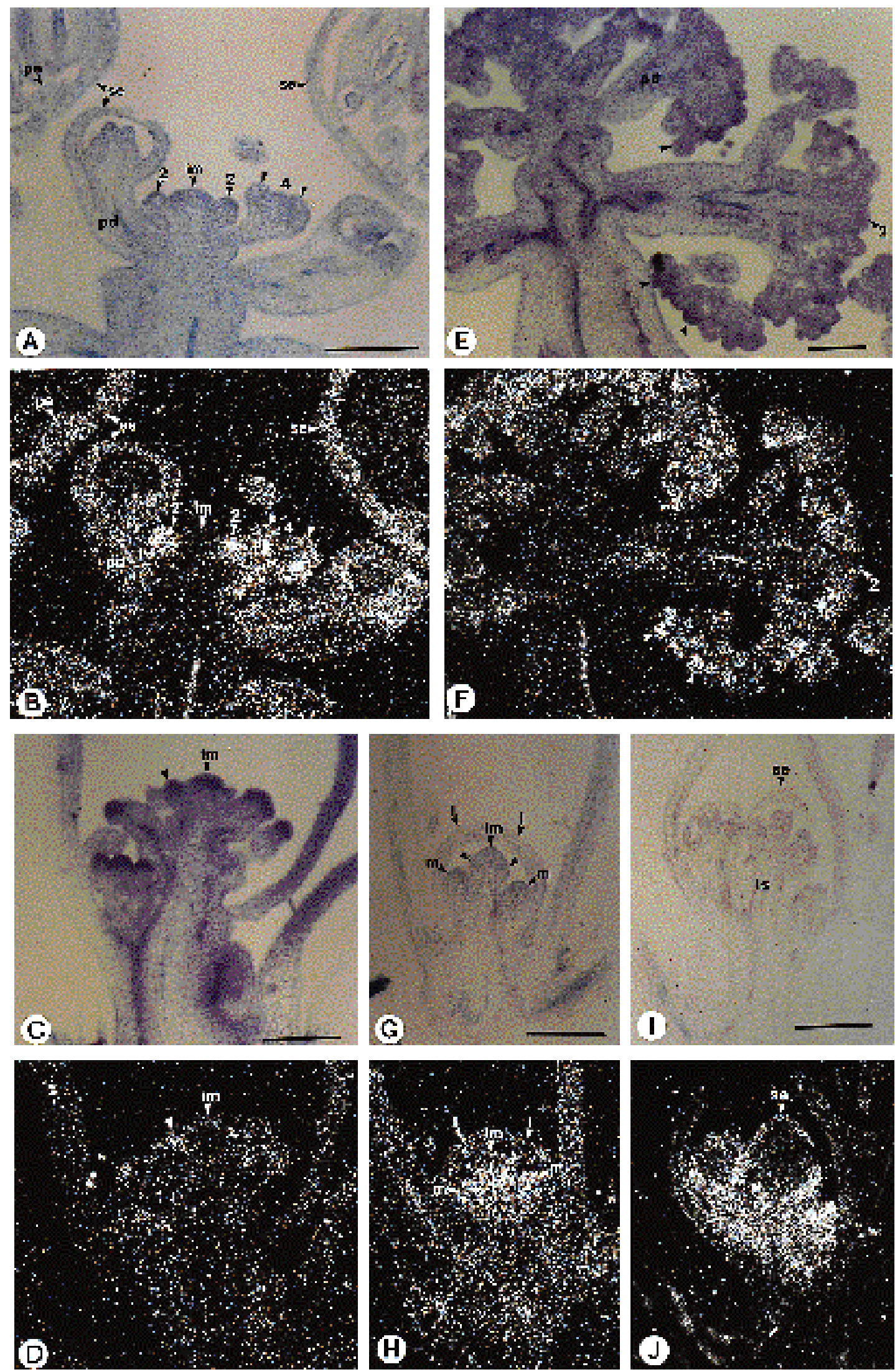
mutant, ap 1-1. Such double mutants have pedicellar and second order inflorescence meristems in their basal positions, structures that are absent in ap 1-5 alone (Table 3). Also, the floral organs that develop in ap 1-5 cal-1 flowers resemble those of ap 1-1 plants in number and type.

Plants homozygous for cal-1 alone closely resemble wild type although the first position above the cauline leaves is often occupied by an inflorescence or a determinate branched structure, a phenomenon that occurs in wild type, but at a much lower frequency. Thus a major effect of cal1 is only seen when it is combined with apl mutants.

\section{Expression pattern of $A P 1$ in cauliflower plants}

Since $A P l$ expression is associated with floral meristems but not inflorescence meristems (Mandel et al., 1992), we examined its expression patterns in ap $1-1$ cal-1 plants at different ages and grown under different environmental conditions.

In wild-type flowers, $A P 1 \mathrm{mRNA}$ is first detected in stage 1 flowers and is uniformly expressed at a high level throughout stage 1 and stage 2 flower primordia (Fig. 5A,B; Mandel et al., 1992). In stage 3-4 flowers, APl mRNA becomes restricted to the first and second whorls of the wild-type Ara bidopsis flower, with no expression detectable in the presumptive third and fourth whorls. Expression is maintained until past stage 12, throughout developing sepals and petals, with no expression detectable in the stamens and carpels. In addition, API mRNA is present throughout the pedicel during flower development but is not detectable in the inflorescence meristem.

The expression of AP1 in apl-1 mutant flowers occurs at normal levels in stage 1-2 flowers (data not shown). In contrast, its expression in apl-1 cal-1 is markedly different. A very low level of $A P 1$ mRNA is detected in young apl1 cal-1 inflorescences (Fig. 5C,D). However, in older inflorescences a level of $A P l$ expression similar to that seen in stage 1-2 of wild-type flowers is observed in some of the higher order meristems (Fig. 5E,F). APl expression appears to occur in the higher order meristems first, regions associated with the later formation of flowers but prior to any morphological evidence of flower development. Also there is an acropetal effect. In branches arising higher up the main stem, APl mRNA accumulates in meristems that have been through only a few orders of branching. In addition, a range of $A P l$ expression is observed in the peduncles and pedicels of the supernumerary meristems, with low expression in those carrying low order meristems and increasing expression in those of higher order meristems. These results are all from plants grown at $25^{\circ} \mathrm{C}$. Very little $A P 1$ expression is observed in the supernumerary meristems of ap 1-1 cal-1 plants grown at $16^{\circ} \mathrm{C}$ (data not shown).

Thus the expression of API in apl-1 cal-1 plants is initially very low in primordia formed on the flanks of inflorescence apices. However, depending on environmental conditions, levels gradually increase in later formed primordia until they reach near wild-type levels. At this stage the primordia are apparently committed to develop as flowers.

\section{Interactions between ap1, cal and terminal flower mutants}

In terminal flower ( $t f l)$ mutant plants, the primary apical inflorescence meristem becomes determinate and its growth terminates in a flower composed of more than the normal number of floral organs (Shannon and Meeks-Wagner, 1991; Alvarez et al., 1992). A few normal flowers may be produced before termination. The inflorescence meristems arising in the axils of the cauline leaves usually produce only a single terminal flower (Alvarez et al., 1992). The if phenotype has been interpreted as a conversion of the inflorescence meristem into a flower meristem (Shannon and Meeks-Wagner, 1991) or an invasion of the inflorescence apex by flower primordia (Alvarez et al., 1992).

Since ectopic flower meristems are formed in $t f$ plants, we examined the pattern of $A P 1$ expression in these meristems. The apical inflorescence meristem, which develops into a terminal flower in $t f l-2$ mutant plants, exhibits ectopic AP1 expression early in its development (Fig. 5G,H). Later expression is present in the outer floral whorls (Fig. 5I,J). In addition, ectopic expression is observed in the inflorescence stem itself, which, in $t f$ plants, acts as the pedicel of the terminal flower. A high level of ectopic APl expression is also detected very early in meristems in the axils of cauline leaves which will develop into individual flowers (Fig. 5G,H). Thus in $t f-2$ plants $A P 1$ expression is initiated at the time when the identity of ectopic flowers is established

Since $t f-2$ and apl-1 cal-1 mutant plants display seemingly opposite effects in the interconversion of flower and inflorescence meristem identities, we constructed all mutant combinations. Firstly, cal- 1 t $f$-2 plants were apparently indistinguishable from $t f-2$ singles in families segregating for both, further evidence that cal-1 influences development only when apl is also mutant. Secondly, apl$1 \mathrm{t} f$ - 2 doubles display an additive phenotype except that the terminal flower on the main inflorescence apex has few if any axillary flowers. Overall the phenotype is close to that of apl-1 t $f$ - 1 plants recorded by Shannon and MeeksWagner (1991). Finally, the triple mutant, ap 1-1 cal-1 tf2 , displays an unexpected phenotype. Its morphology is indistinguishable from that of the ap $1-1 \mathrm{t} f$ - 2 double mutant (Fig. 4L), meaning that $t f$ is fully epistatic to cal- 1 in ap1-1 mutant background. Furthermore, even heterozygosity for $t f-2$ reduces the enhancement by $c a l-1$ of the ap 1-1 mutant phenotype. In ap 1-1 cal-1 plants heterozygous for $t f l-2$ a maximum of three rounds of meristem proliferation is observed, in basal positions, before flowers differentiate.

\section{Interactions between ap1, cal and leafy mutants}

Like ap1, mutations of the $L E A F Y(L F Y)$ gene also result in the partial transformation of flower meristems into inflorescence meristems (Schultz and Haughn, 1991; Weigel et al., 1992; Huala and Sussex, 1992). The basal positions in strong lfy mutants exhibit complete transformation of flowers to inflorescence shoots, while the more apical flowers are only partially converted (Fig. 6A). However, a major difference from apl is that the basal transformed inflorescences are usually subtended by a cauline leaf and the upper 'flowers' by a bract in lfy mutants. Also, the organs that arise in lfy 'flowers' are more leaf-like, are often initiated in a spiral, leaf-like manner (interior to a cruciform first whorl) and significant internode elongation may occur 

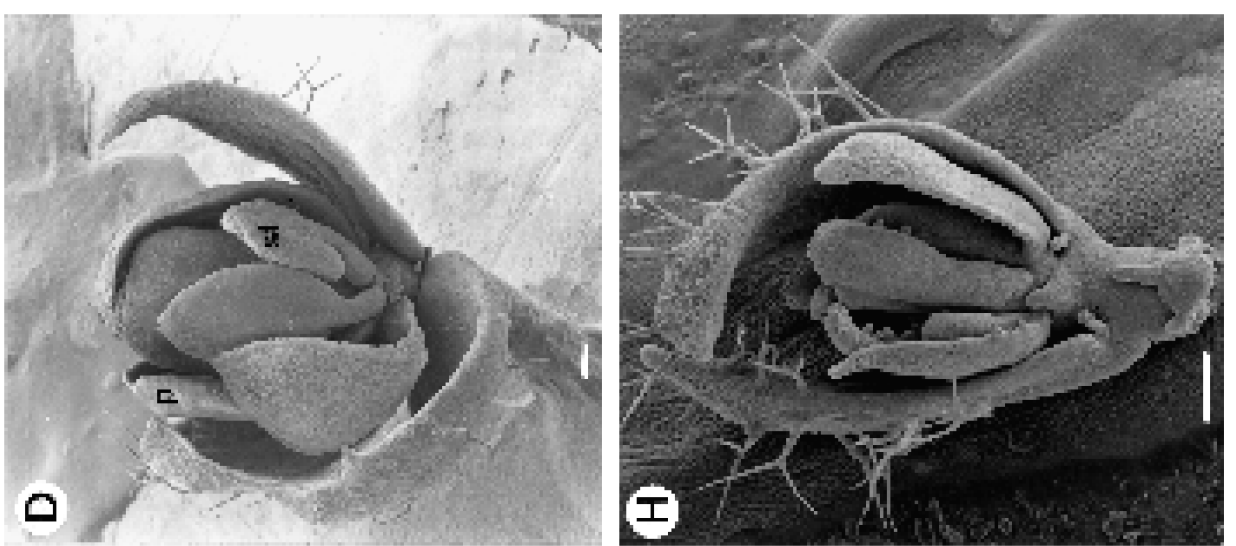

분

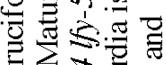

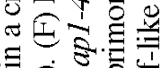

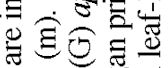

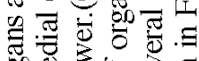

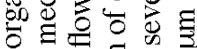

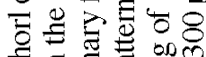

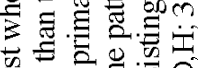

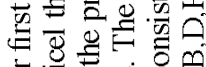

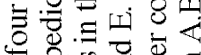

o

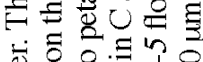

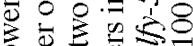
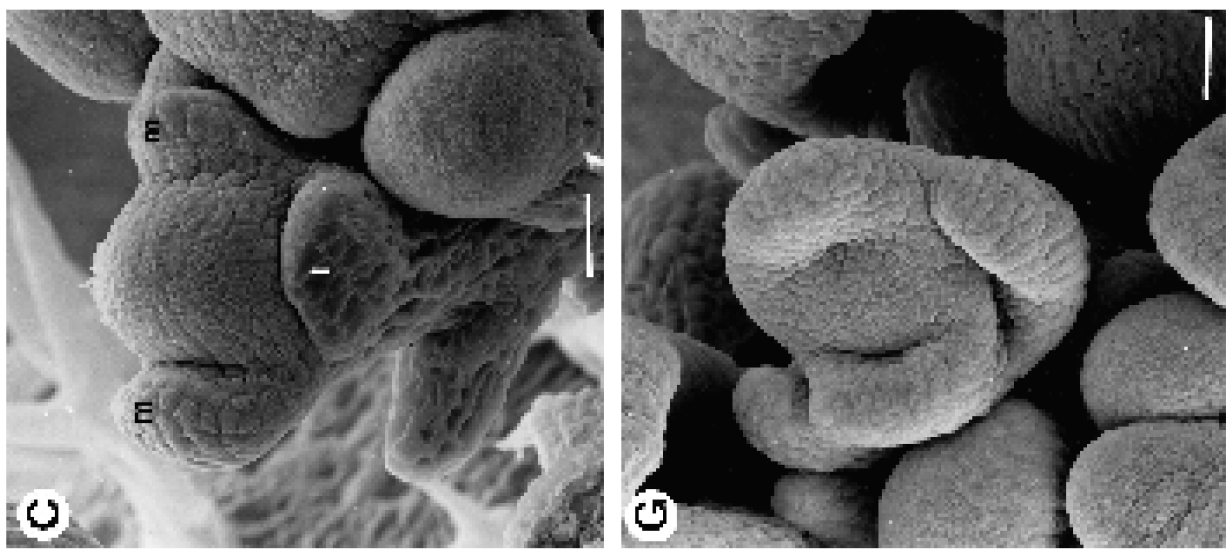

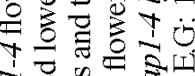

今心

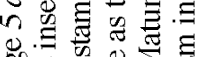

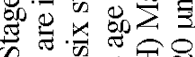

$\widehat{\vartheta}=$

凷范范

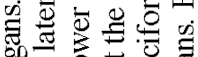

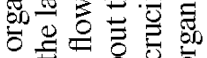

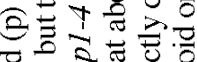

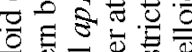

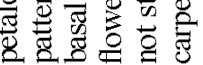
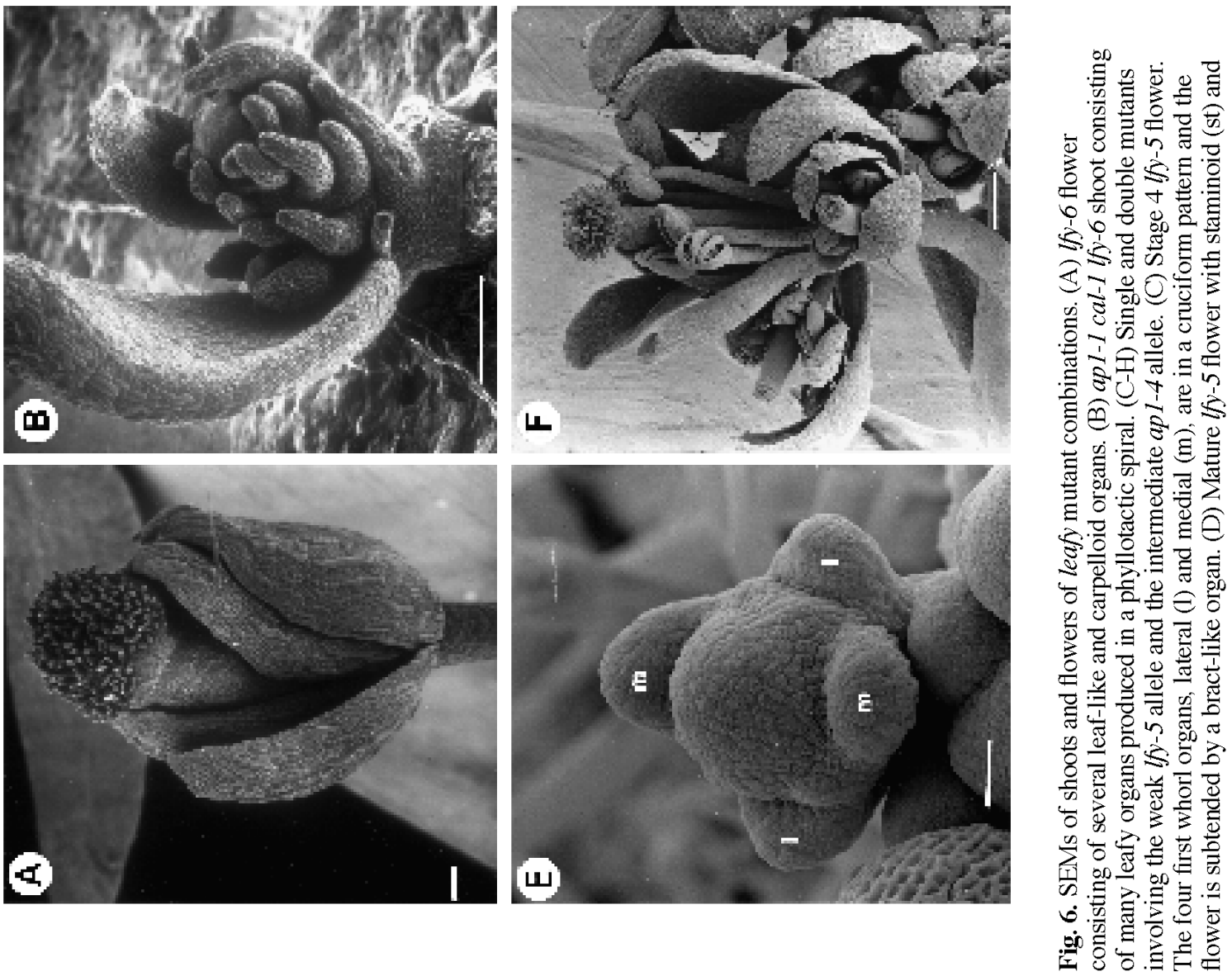
between the organs (Weigel et al., 1992). Finally, secondary flowers are less frequent than in apl mutants.

The $A P I$ and $L F Y$ gene products apparently interact to specify floral meristem identity. Evidence for this comes from studies of double mutants. A significant enhancement of the lfy phenotype occurs when strong or weak lfy alleles were placed in double mutant combination with the strong mutant ap1-1 (Weigel et al., 1992; Huala and Sussex, 1992).

We have found a similarly dramatic interaction between the intermediate ap 1-4 allele and the weak $l f y-5$ allele, indicating that an interaction does not depend on a complete loss of $A P 1$ function. While petals and stamens are common in flowers of apl-4 (Table 5; Fig. 6F) and in apical flowers of lfy-5 (Fig. 6D; Weigel et al., 1992), apl-4 lfy-5 flowers consist entirely of leaf-like, carpelloid leaf-like and carpelloid organs (Fig. 6G,H). The phyllotaxy of the organs is often intermediate between spiral and whorled (Fig. 6G, compare Fig. 6C and Fig. 6E). In addition, flowers now develop in the axils of some of the leaf-like organs. The axillary flowers are much reduced, often consisting of only two or three carpels. The primary inflorescence meristem of ap 1-4 lfy-5 plants usually terminates in a mass of carpelloid tissue as in strong lfy plants (Weigel et al., 1992).

To examine if lfy and cal interact when in mutant form in the same way as do $a p l$ and $c a l$, plants were bred that carried both lfy- 6 and cal-1. Strikingly, their phenotype could not be distinguished from that of lfy- 6 single mutants indicating a major difference between $A P I$ and $L F Y$ in their relationship with $C A L$. This was reinforced when the phenotype of the triple mutant ap1-1 cal-1 lfy-6 was examined (Fig. 6B). Such plants were indistinguishable from apl-1 lfy-6 double mutants (Weigel et al., 1992), showing that lfy-6 is fully epistatic to cal-1 in an apl-1 background.

\section{Expression pattern of LEAFY in cauliflower plants}

Because the apl cal mutant combination apparently results in a prolonged loss of the ability to specify floral meristem identity at $25^{\circ} \mathrm{C}$, we analyzed the expression of the $L F Y$ gene product in apl cal inflorescences grown at this temperature.

In wild-type flowers, $L F Y$ mRNA is first detected at a low level in cauline leaf primordia and then in the flanks of the inflorescence meristem in the floral anlagen (precursor) cells (Fig. 7A,B; Weigel et al., 1992). It is uniformly expressed at a high level throughout stage 1 and stage 2 flower primordia, but in flowers later than stage $4 L F Y$ mRNA becomes preferentially localized to particular differentiating organs such as the carpels and stamen filaments. Unlike $A P 1, L F Y$ expression is not significant in floral pedicels.

Whereas early $L F Y$ expression is normal in ap 1-1 single mutants (Weigel et al., 1992), expression in apl-1 cal-1 double mutants is, like $A P 1$, drastically altered. Only low levels of $L F Y$ transcript are observed in the basal-most primordia produced by young apl-1 cal-1 inflorescence meristems (Fig. 7C,D). These levels range from those observed in wild-type cauline leaf primordia to those in floral anlagen. However, a level of $L F Y$ expression comparable to that observed in stage 1-2 wild-type flowers is seen in older apl-1 cal-1 inflorescences (Fig. 7E,F). As in AP1, there is a marked acropetal effect. The expression of $L F Y$ is greatest in the higher order primordia, those from which mature flowers are likely to soon develop (Fig. 7E,F).
Fig. 7. Expression patterns of $L E A F Y$ in apl cal plants. In situ hybridization of a $L F Y$ anti-mRNA probe with longitudinal sections $(8 \mu \mathrm{m})$ through wild-type $(\mathrm{A}, \mathrm{B})$ and ap 1-1 cal-1 (C-H) inflorescence apices. Each section was photographed in two ways: bright field (A,C,E,G) and dark field (B,D,F,H). (A,B) Wild type. A low level of $L F Y$ expression is first detected in floral anlagen (a) on the flanks of the inflorescence meristem (im). In stage 1-2 flower primordia, a high level of $L F Y$ expression is observed throughout the primordia, as seen in the two stage 2 flowers (2). In older flowers, $L F Y$ expression is concentrated in certain differentiating organs such as carpels (c). (C,D) Young apl-1 cal1 inflorescence apex grown at $25^{\circ} \mathrm{C}$ (similar to that in Fig. 4C). A low but significant signal is seen in some of the meristems (arrowhead) produced by the apical inflorescence meristem (im). (E,F) A second order branch of an older ap 1-1 cal-1 inflorescence grown at $25^{\circ} \mathrm{C}$ (similar to that in Fig. $4 \mathrm{~F}$ ). $L F Y$ signal comparable to that of wild-type stage 2 flowers is seen in the higher order meristems (e.g. arrowheads), but little signal is observed in the second order inflorescence meristem itself (2) or in the lower order supernumerary meristems surrounding it.

$(\mathrm{G}, \mathrm{H})$ Inflorescence apex of an ap 1-1 cal-1 plant grown at $16^{\circ} \mathrm{C}$ (similar to that in Fig. $4 \mathrm{~J}$ ). Little $L F Y$ signal is observed in any of the proliferating meristems or any of the subtending leaves. A leaf (1) and a second order inflorescence meristem (2) analogous to that in $\mathrm{E}$ are indicated. Bars, $200 \mu \mathrm{m}$. Each autoradiograph is shown at the same magnification as its corresponding bright-field micrograph.

Strikingly, as with $A P 1$, very little $L F Y$ expression is detected in any of the supernumerary meristems of apl-1 cal-1 plants grown at $16^{\circ} \mathrm{C}($ Fig. $7 \mathrm{G}, \mathrm{H})$.

\section{Interactions between ap1 and floral homeotic mutants}

Since mutations at the $A P I$ locus also affect floral organ identity, we constructed combinations of various apl mutants with floral homeotic genes controlling floral organ specification (Table 2; Bowman et al., 1989; 1991).

\section{apetala1 apetala2 double mutants}

Mutations in apetala2 (ap2), like ap1, affect the outer two whorls. In flowers of strong ap 2 mutants (Fig. 8A), the medial first whorl positions are occupied by solitary carpels, while the lateral positions either lack organs or are occupied by leaf-like organs. No second whorl organs are present and the number of third whorl stamens is reduced to an average of less than one per flower (Bowman et al., 1991). Flowers of weak ap2 mutants have a first whorl of leaf-like organs, with occasional axillary flowers in the basal positions (10 occurrences in 20 flowers at $25^{\circ} \mathrm{C}$ ). Organs that are intermediate between petals and stamens occupy the second whorl (Fig. 8D; Bowman et al., 1989; 1991). The severity of changes in organ identity of all ap2 alleles increases acropetally and with environmental conditions (Bowman et al., 1989; 1991) as in apl alleles.

In terms of organ identity, strong ap2 alleles are largely epistatic to both strong and weak apl alleles. For example, in ap 1-1 ap2-2 flowers (Fig. 8B,C), the medial first whorl organs, when present, are carpels and the lateral first whorl positions are generally lacking fully developed organs, although there may be aborted primordia in these positions. There are no second and few third whorl organs. When present third whorl organs are either stamens or carpelloid 

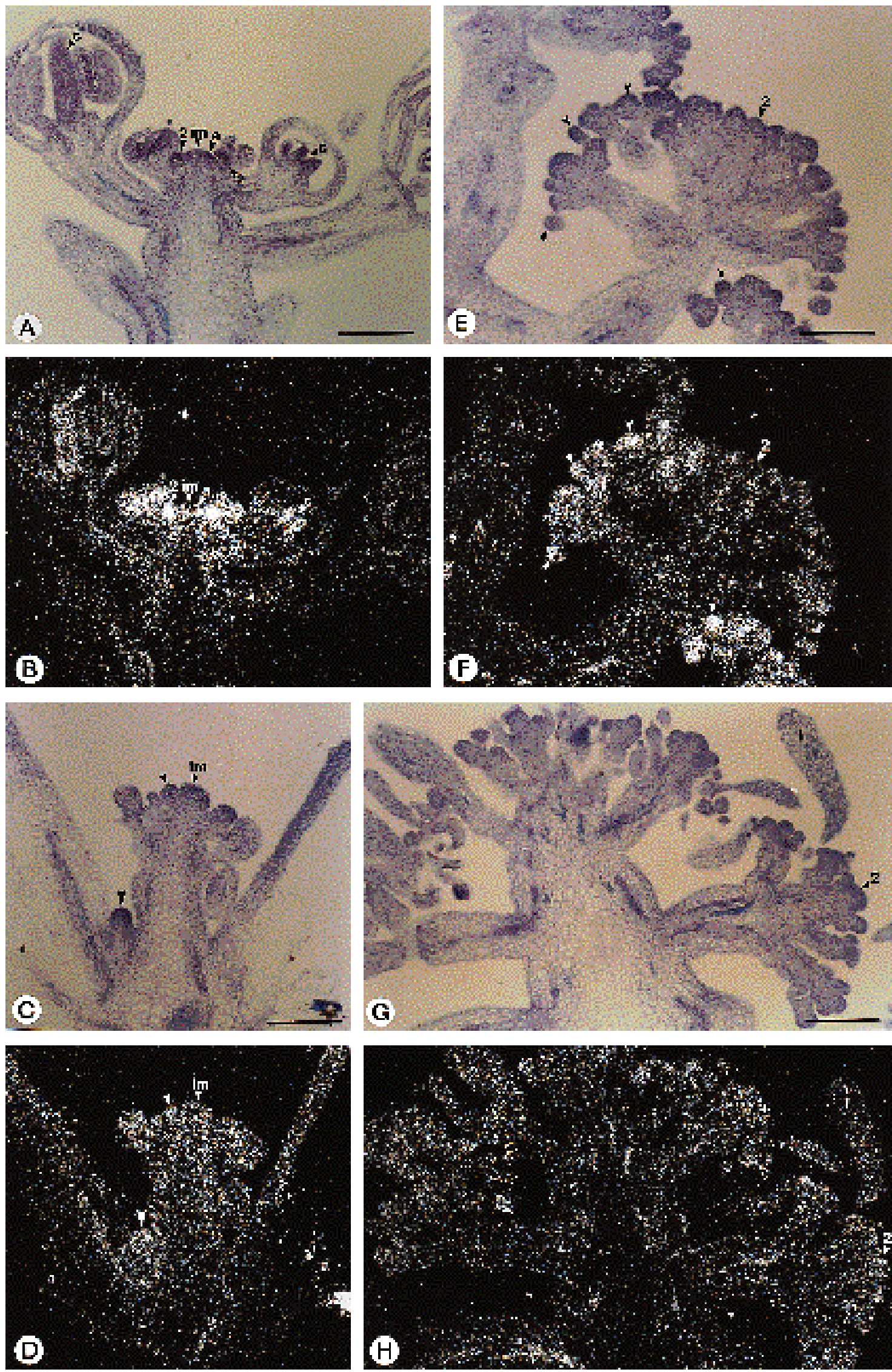
Table 6. Mean number of flowers per pedicel/peduncle in ap1 ap2 plants

\begin{tabular}{lccc}
\hline & \multicolumn{3}{c}{ Genotype } \\
\cline { 2 - 4 } & ap1-1 & ap1-1 ap2-1 & ap1-1 ap2-2 \\
\hline flowers 1-5 & 9.1 & 20.0 & 3.5 \\
flowers 6-10 & 3.7 & 7.7 & 2.8 \\
flowers 11-15 & 2.1 & 4.8 & 2.4 \\
$\quad$ second order & 5 & 2 & 42 \\
$\quad$ inflorescences & & & 13 \\
no. of plants scored & 16 & 8 & \\
All plants were grown at $25^{\circ} \mathrm{C}$. & & \\
See Table 3 for explanation. & & \\
\hline
\end{tabular}

stamens, and the fourth whorl carpels often fail to fuse properly and may also have sectors of stamen tissue. In the more apical positions, the primary flower of ap1-1 ap2-2 double mutants consists of only a single gynoecium composed of 2 to 4 carpels. This is also observed in ap2-2 single mutant flowers. Flowers of other double mutant combinations, ap1-5 ap2-2, ap1-1 ap2-9 and ap1-6 ap2-9, also resemble those of the respective ap 2 single mutants (results not shown).

In contrast, a dramatic interaction is observed in double mutant combinations of apl with the weak allele ap2-1. For example, when ap1-5 (a weak allele) and ap2-1 are combined, the resulting double mutant flower (Fig. 8E) closely resembles that of the strong ap2-2 allele (Fig. 8A). The medial first whorl organs are now most often carpels, although in the single mutants these positions are occupied by organs that are bract-like (ap1-5, Fig. 3D) or leaf-like (ap2-1, Fig. 8D). No second whorl organs form, even in the basal flowers. Their development (Fig. 8F) is also similar to that of ap2-2 (Bowman et al., 1991). Much stronger mutant phenotypes are also seen when ap2-1 is combined with ap 1 1 or ap 1-2 (results not shown).

Weak ap2 mutants also enhance the inflorescence character of the branched floral structures of ap 1-1 mutants. In ap1-1 ap2-1 double mutants, determinate structures composed of upwards of 50 flowers have been observed developing from positions that in wild type would be a single flower (Table 6; Irish and Sussex, 1990). In contrast, in double mutant combinations involving strong ap2 mutants, such as ap1-1 ap2-2, this effect is reversed such that the determinate branched structures are seldom composed of more than ten flowers (Table 6). However in this case the frequency of second order inflorescence meristems is increased (Table 6).

\section{apetala1 agamous double mutants}

agamous (ag) mutants affect the identity of the third and fourth whorl. Third whorl organs develop into petals instead of stamens and cells that would normally give rise to a fourth whorl gynoecium behave instead like another flower meristem. Thus ag flowers are indeterminate and consist of a large number of whorls of sepals and petals (Fig. 8G)

Flowers of double mutant plants carrying strong apl and $a g$ alleles such as $a p 1-1$ and $a g-1$ often appear to consist of an indeterminate number of whorls of bract-like organs with flowers arising in the axils of some of the organs of the first and internal whorls (Irish and Sussex, 1990). The bract-like
Fig. 8. SEMs of apetalal apetala2 (A-F) and apetalal agamous (G-L) flowers. (A) Mature ap2-2 flower. The medial first whorl organs are solitary carpels (c), no second whorl organs are present and three staminoid organs occupy the third whorl. (B) Mature ap1-1 ap2-2 flower consisting of 5 solitary carpels and a stamen. The secondary flower (arrowhead) composed of a two-carpelled gynoecium is not subtended by any organ. (C) A developing ap 11 ap2-2 flower at around stage 8, showing an incompletely fused gynoecium $(\mathrm{g})$, a medial first whorl organ which is carpelloid (m) and an aborted lateral first whorl organ (1). Also visible is a younger stage 4 flower (4). The development of these double mutant flowers resembles that of ap2-2 single mutants (Bowman et al., 1991). (D) Mature ap2-1 flower consisting of an outer whorl of leaf-like organs, a second whorl of three staminoid petals (arrowheads), five third whorl stamens and a central gynoecium. (E) Mature ap 1-5 ap2-1 flower. The medial first whorl positions are occupied by two carpels (c), of which the one on the right has a staminoid sector, a phenotype frequently observed in strong ap2 alleles (Bowman et al., 1991). Three staminoid third whorl organs surround a central gynoecium. The phenotype of ap1-5 ap2-1 flowers resembles that of ap2-2 flowers (A), rather than that of ap1-5 (see Fig. 3D) or ap2-1 (D) flowers. (F) Vertical view of an ap1-5 ap2-1 inflorescence. The inflorescence meristem (im), a stage 4 and a stage 7 flower are indicated. In the stage 7 flower, there is a reduction in floral organ number and the gynoecial primordium is abnormally shaped. The development of these weak double mutant flowers resembles that of intermediate to strong ap2 mutants (Bowman et al., 1991). (G) Mature ag-1 flower consisting of an outer whorl of sepaloid organs and an indeterminate number of internal whorls of petaloid and sepaloid organs. $a g-1$ and $a g-3$ flowers are indistinguishable. $(\mathrm{H})$ Early developing ap 1-1 ag-1 flower. An axillary flower bud (f) is visible in the axil of a first whorl organ. The pattern of organ primordia internal to the first whorl is irregular. (I) Later developing ap 1-1 $a g-1$ flower. Four axillary floral buds (f) are visible. The pattern of organ primordia produced by the floral meristem $(\mathrm{m})$ is irregular. (J) Mature ap 1-7 ag-3 flower. Two prominent axillary flowers are visible, as well as two more internal axillary floral buds (arrowheads). The internal whorls consist of petaloid and bractlike organs. (K) Close up of the abaxial surface of a petaloid organ from an ap 1-7 ag-3 flower. The epidermal cells exhibit a mixture of petaloid properties (cobblestone-like cells) and phylloid characteristics (such as stomata). (L) Close up of the adaxial surface of a petaloid organ from an apl-7 ag-3 flower. The epidermal cells are nearly indistinguishable from those of wildtype petals. Bar, $10 \mu \mathrm{m}$ in $\mathrm{L} ; 20 \mu \mathrm{m}$ in $\mathrm{C}, \mathrm{F}, \mathrm{H}, \mathrm{I}, \mathrm{K} ; 100 \mu \mathrm{m}$ in A,B,D,E,G,J.

organs are occasionally carpelloid (about 1 occurrence per plant). However, further inspection reveals that some of the internal organs are often petaloid (Fig. 8K) and near wildtype petals may be common (Fig. 8L).

The development of the first whorl of ap 1-1 ag-1 flowers resembles that of apl-1 flowers, with bract-like organs and axillary flowers occupying those positions (Fig. 8H,I). The pattern of organ primordia interior to the first whorl, in the region of the second and third whorls, is irregular (Fig. $8 \mathrm{H}, \mathrm{I})$. This developmental program may repeat itself several times, similar to the pattern seen in $a g-1$ flowers. However, unlike $a g l$, the floral meristem may soon revert to an inflorescence meristem and produce floral meristems on its flanks in a phyllotactic spiral. This is related to another feature of the apl-1 ag-1 phenotype, conversion of the flower meristem to a second order inflorescence meristem (Fig. 1D). This occurs at a higher frequency in apl-1 ag-1 double 

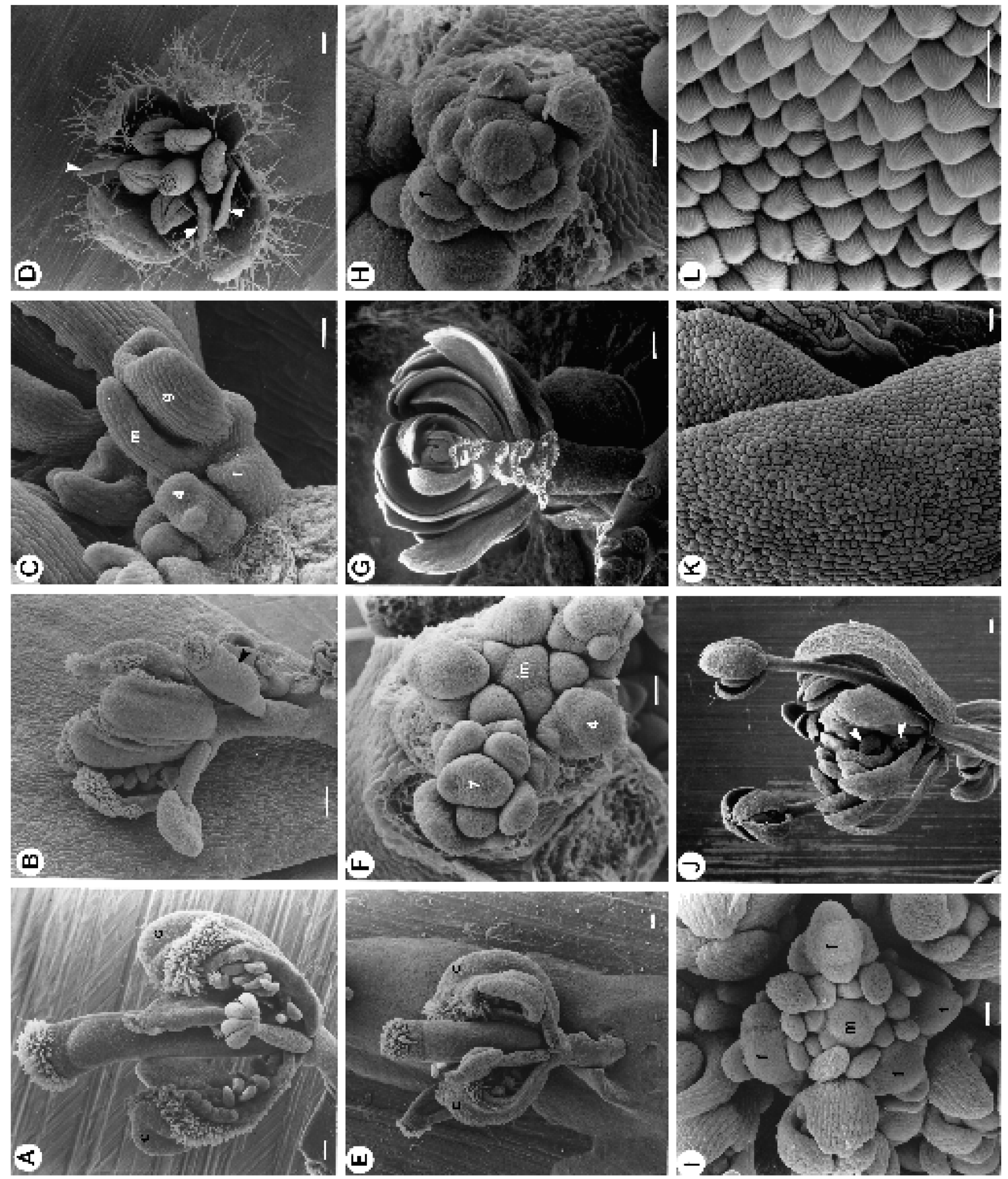
mutants (26 occurrences in 16 plants) than in ap $1-1$ alone (7 in 20 plants).

\section{apetala1 apetala2 agamous triple mutants}

Because $A P 1$ seems to interact with both $A P 2$ and $A G$, and the latter also interact (Bowman et al., 1991; Drews et al., 1991), we were interested to examine the phenotype when all three were in mutant form. In ap1-1 ap2-2 ag-1 triply mutant plants (all strong alleles) the striking observation is that 'flowers' proliferate extensively, producing an indeterminate number of primordia which remain relatively undifferentiated. Interspersed among them are leaf-like organs which are occasionally carpelloid (Fig. 9A). No structure recognizable as a floral organ was ever seen to differentiate, apart from the slightly carpelloid leaf-like organs. On the basis of the size, shape and pattern of initiation, the primordia appear to be a combination of inflorescence meristems, flower meristems and organ primordia (Fig. 9DI).

This is seen more clearly in an analysis of developing structures (Fig. 9B,C). The pattern in which the primordia arise is sometimes spiral (as in inflorescence meristems), sometimes whorled (as in flower meristems) and sometimes intermediate (Fig. 9D-I). Those meristems that produce whorled primordia initially generate a first whorl of bractlike organs, each with an associated axillary meristem. It then either produces another whorl of similar organs (Fig. $9 \mathrm{H})$, reverts to producing meristems in a phyllotactic spiral (i. e. it acts like an inflorescence meristem, Fig. 9E), or behaves intermediately between these two extremes (Fig. 9I).

\section{DISCUSSION}

\section{AP1 controls two stages of floral development}

Our study of an allelic series of apl mutants demonstrate that the APETALAl gene is required early in the determination of flower meristem identity, and later during initiation and development of floral organs. Disruption of the early function results in the partial transformation of flowers into inflorescence shoots. Disruption of the later function causes failure of flower organ initiation and changes in floral organ identity, predominantly in the outer two whorls. These two effects are separable in apl mutants. Inflorescence properties are weaker in later formed flowers on a plant whereas floral organ changes are stronger. Also the weakest mutant alleles display only the late phenotype. The two-fold activity of $A P 1$, as inferred from genetic analysis, correlates well with the biphasic expression pattern of APl RNA (Mandel et al., 1992). We will discuss the two stages in turn.

\section{$A P 1$ interacts with $L F Y$ in controlling floral meristem identity}

Early effects of apl mutants result in flower meristems taking on some of the properties of inflorescence meristems. The stronger the mutant allele, the more often the 'flowers' grow in an indeterminate, inflorescence-like pattern, and the more often secondary and higher order flowers arise in the axils of the outer floral organs (Table 3). The strongest mutant alleles studied here (alleles 1,7 and 9) do not result in a complete transformation. Even so it seems likely that they result in full loss of AP1 function. They have closely similar phenotypes as expected of null mutants. Also the ap 1-1 allele has been sequenced and it carries a splice site acceptor mutation in the third exon (Mandel et al., 1992). This would result in loss of part of the $\mathrm{K}$ box, a conserved domain downstream of the MADS box with sequence similarity to the coiled-coil domain of keratins (Ma et al., 1991). While not necessarily producing an inactive product, the ap 1-1 mutation would seem likely to severely disrupt its function (Yanofsky et al., 1990; Ma et al., 1991).

Much more complete flower-to-inflorescence transformations can be obtained if strong apl mutants are combined with strong lfy mutants, which independently cause partial flower-to-inflorescence conversions (Huala and Sussex 1992; Weigel et al., 1992). Even in combinations of the intermediate ap 1-4 mutant and the weak lfy-5 mutant, we have found that flower-to-inflorescence transformations are greatly enhanced. This suggests that the products of $A P 1$ and $L F Y$ normally interact to reinforce each others activity to specify flower meristem identity. The other four genes studied here also interact with apl and/or lfy when in mutant form. However, none has a significant effect on the identity of flower meristems when mutant alone. It seems that $A P 1$ and $L F Y$ are the major players in the specification of floral meristem identity and that the other genes have secondary or partially redundant roles.

\section{Basis of early actions of $A P 1$ and $L F Y$}

Firstly, it appears that the initial activation of $A P I$ and $L F Y$ is coincident with floral induction. In Arabidopsis, factors that mediate floral induction seem to be promoted by long days and higher temperatures (Napp-Zinn, 1985). Both APl and $L F Y$ appear to be responsive to (i.e. activated by) these same factors. The evidence for this is as follows. In apl single mutants, where $L F Y$ is still functional (Weigel et al., 1992), transformation of flower meristems to inflorescence meristems is much more complete if flowering is held in check by lower temperatures (Table 3 ) or short days (Huala and Sussex, 1992). This suggests that $L F Y$ expression also remains at relatively low levels under these conditions, allowing prolonged, inflorescence-like growth. Likewise in lfy mutants, where $A P l$ is still functional, lower temperatures (Weigel et al., 1992) and short days (Huala and Sussex, 1992) result in more complete inflorescence-like transformations. Activation of the two genes by those factors that mediate floral induction could also explain the fading of inflorescence-like properties in later-arising flowers of both apl and lfy mutants. This is expected if levels of the factors controlling floral induction progressively increase as an induced plant ages.

Secondly, it seems that a threshold level of a factor (or factors) regulated by both $A P I$ and $L F Y$ must be exceeded for the complete specification of floral meristem identity to occur. It seems that the $A P I$ and $L F Y$ gene products act in a partially redundant manner in ensuring that this threshold is reached. If the activity of either gene is compromised by mutational change, the other can work to a limited extent to allow the threshold level to be obtained. The meristem then takes on some of the properties of a flower, the particular properties dependent on which downstream functions are 

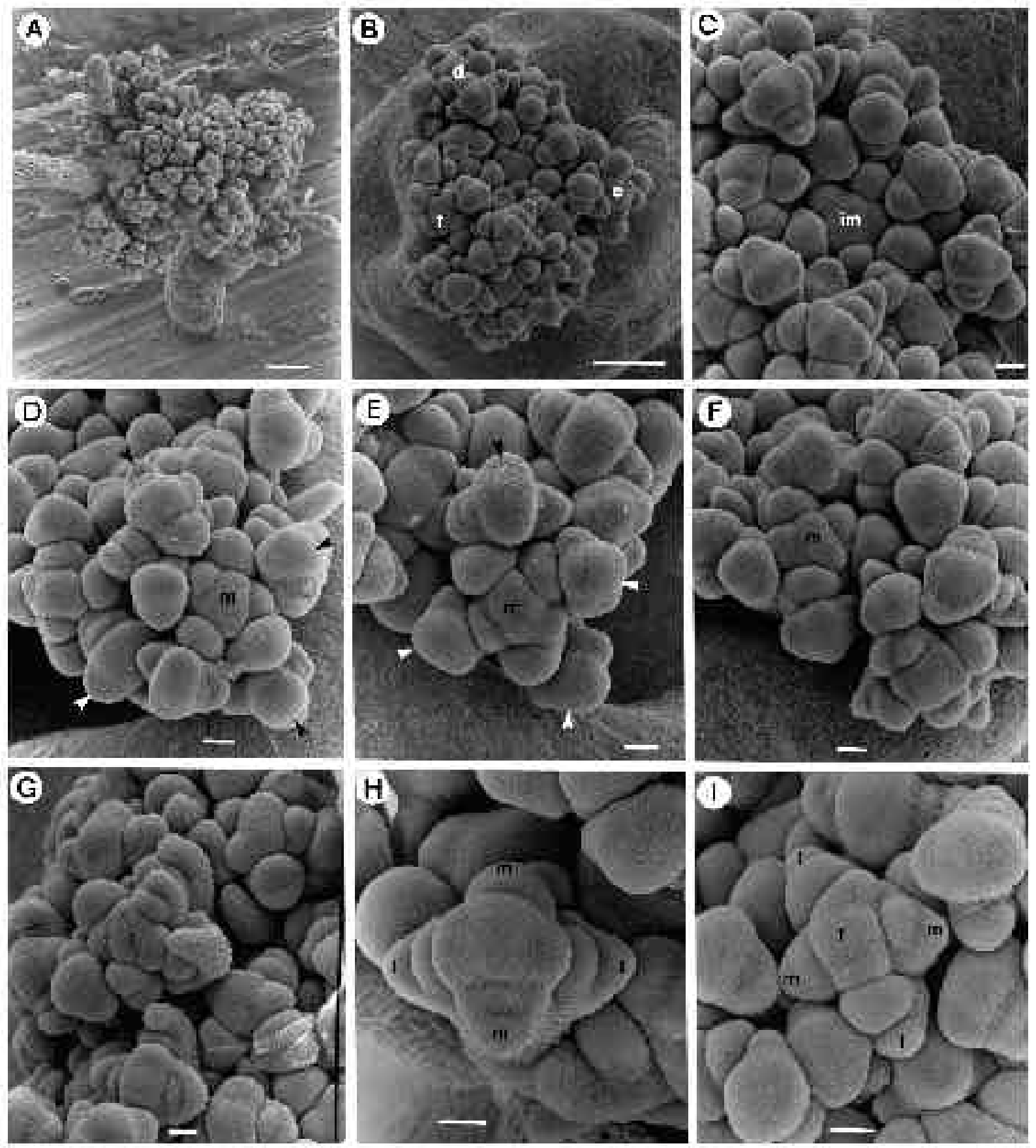

Fig. 9. SEMs of apetalal apetala2 agamous inflorescences and flowers. (A) Mature apl-1 ap2-2 ag-1 flower. This structure consisting of numerous undifferentiated primordia and some leaf-like organs all of which have developed from a single floral meristem. (B) Young ap1-1 ap2-2 ag-1 inflorescence. Flowers labelled d, e and f are shown in detail below. (C) Close up of the center of B showing the youngest flowers and the apical inflorescence meristem (im). (D-E) Close up of flowers labeled d and e, respectively, in B. Interior to four axillary meristems in a somewhat cruciform phyllotaxy (arrowheads) the floral meristem $(\mathrm{m})$ is producing primordia in a phyllotactic spiral. The 'flower' in E is similar to that in D only at a younger developmental age. (F) Close up of 'flower' labelled $\mathrm{f}$ in B showing the floral meristem (m). (G) ap 1-1 ap2-2 ag-1 flower consisting of organs with axillary meristems and other primordia in addition to the floral meristem (f). Other floral structures can be seen with both spiral and whorled phyllotaxy. (H) apl-1 ap2-2 ag-1 flower showing cruciform phyllotaxy and axillary meristems associated with both lateral (1) and medial (m) first whorl organs. (I) apl-1 ap2-2 ag-1 flower with phyllotaxy intermediate between spiral and whorled. Four first whorl organs are present, lateral (l) and medial (m), each with an associated axillary meristem surrounding the floral meristem (f). Bar, $20 \mu \mathrm{m}$ in C-I; $100 \mu \mathrm{m}$ in A,B.

lacking (see below). If the threshold level is not reached (as in the strong double mutant), the meristem behaves as an inflorescence meristem. This threshold proposal, combined with the proposed progressive strengthening of the factors promoting floral induction, also allows a relatively simple explanation for the overlapping patterns of acropetal 
variation shown by the strong, intermediate and weak allelic series of both apl and lfy mutants. The weaker the mutational change, the sooner the threshold is reached and the earlier any inflorescence-like properties are lost.

Thirdly, it seems likely that, once present, the wild-type $A P I$ and $L F Y$ gene products mutually enhance each other's activity (Fig. 10). This is proposed to account for the considerably greater disruption of phenotypes seen when weak or intermediate apl and lfy mutants are combined. The enhancement seems to be primarily at the level of activation of target genes rather than through directly influencing each other's transcription because each is transcribed when the other is in mutant form (see above). Such mutual enhancement, in combination with the requirement that threshold levels of activity be reached, provides a basis for the sharp transition between the production of inflorescence meristems and flower meristems seen in wild type, and the gradual transition observed in apl and lfy mutants.

Finally, although $A P I$ and $L F Y$ act in combination to specify the identity of the floral meristem, their early roles are not equivalent. In lfy but not apl mutations the main apex continues to produce cauline leaves/bracts. It could be that $L F Y$ but not $A P 1$ has a role in suppressing bract formation (Schultz and Haughn, 1991; Weigel et al., 1992). This may depend on the low level of $L F Y$ expression observed in the anlagen of floral meristems even before stage 1 (Figs 7, 10). Another difference between API and $L F Y$ functions lies in development of the stems of individual flowers. $A P I$ but not $L F Y$ is expressed in developing pedicels (Figs 5, 7; Mandel et al., 1992; Weigel et al., 1992). The phenotype of apl mutants indicates that AP1 activity is needed to identify this tissue as floral stem, suppressing its potential to develop ectopic floral and inflorescence meristems (Fig. 1B) and preventing its elongation.

\section{The role of CAULIFLOWER}

Neither $A P 1$ nor $L F Y$ is expressed significantly in the early primordia of ap 1-1 cal-1 double mutants (although both are in ap 1-1 singles). This formally suggests that the expression of both genes is positively regulated, either directly or indirectly, by the $C A L$ gene product.

A simple scheme for $C A L$ function is that, in combination with $A P 1$, it elevates the expression of $L F Y$ and $A P 1$ in early flower primordia (Fig. 10). $L F Y$ expression is greatly reduced compared to wild type in the first primordia produced by the main inflorescence meristem in ap $1-1 \mathrm{cal}$ 1 plants (Fig. 7C,D). Even so LFY seems to be at a high enough level to suppress bract (cauline leaf) development although not enough to allow any floral characters to develop. This leads to the proliferation of multiple, undifferentiating inflorescence meristems. However, LFY activity seems to gradually accumulate in the higher order meristems of apl-1 cal-1 plants (Fig. 7E,F), eventually reaching a level required for floral meristem specification. Flowers then develop and mature. We have proposed above that $L F Y$ expression is relatively low at low temperatures because of the reduced strength of factors inducing floral development. The phenotype of apl-1 cal-1 plants raised at $15^{\circ} \mathrm{C}$ is consistent with this. The level of $L F Y$ is not sufficient any more to suppress bract formation consistently and,

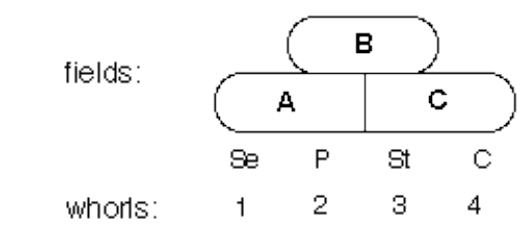

flower

anlagen

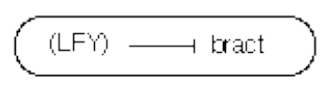

stages 1-2 (flower primordium)

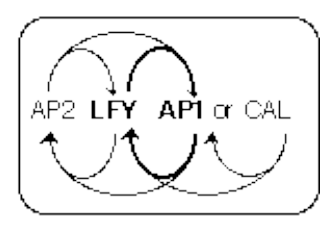

stages 3-4 (first whort organ primordia present)

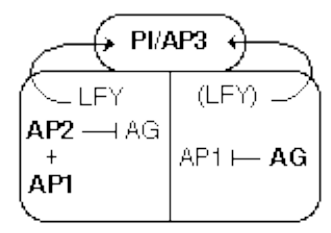

stages $5-7$
(all floral
organ
primordia
present)

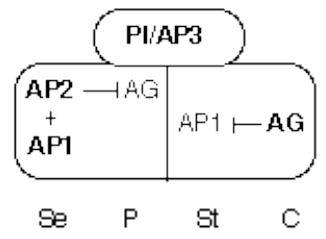

Fig. 10. Cartoon of how known gene products may interact in the specification of floral meristem identity and floral organ identity. A section through one half of a floral primordium is represented as a set of boxes, with the regions representing each whorl and field indicated at the top. The types of organs occupying the four whorls in wild-type flowers are also indicated: Se, sepal; P, petal; St, stamen; C, carpel (Bowman et al., 1991). Arrows represent positive interactions and barred lines represent negative interactions. It should be emphasized that these interactions may be either at the level of a direct influence of each other's transcription or at the level of regulation of downstream target genes. Genes in bold indicate more important activities; genes in parentheses denote relatively low levels of activity. The four lower diagrams represent successively later stages of flower development as defined in Smyth et al. (1990). In the floral anlagen, a low level of LFY activity is required to repress bract formation. During stages 1 and 2, each of the four genes ( $A P 2$, $A P 1, L F Y$ and $C A L)$ are active throughout the primordium. They act in combination, with $A P I$ and $L F Y$ the major players, to specify the identity of the floral meristem. During stages 3 and 4 , organ identity genes are expressed in the meristem in three overlapping fields. Field A is represented by AP1 and AP2 activities and field $\mathrm{A}$ function requires their combined presence. Field $\mathrm{C}$ function is associated with $A G$ expression in the inner two whorls. Field $\mathrm{A}$ and field $\mathrm{C}$ functions are mutually antagonistic because the expression of $A P 1$ is repressed by AG activity in the inner two whorls (Mandel et al., 1992) and expression of $A G$ is repressed by AP2 in the outer two whorls (Drews et al., 1991). Field B genes $P I$ and AP3 also come on at this stage. AP1, AP2 and LFY probably still positively interact although this is not shown. By the time that all the floral organ primordia have formed (stages 5-7), the three fields of gene activity are established and act to specify organ identity. 
apparently, it never reaches the threshold at which flowers are specified, even in apical positions (Fig. 7G,H)

The expression of $A P 1$ parallels that of $L F Y$ in apl-1 cal1 plants (Fig. 5), suggesting that $A P l$ is also positively regulated by $C A L$. These proposals also account for the fact that the ap 1-1 cal-1 lfy-6 triple mutant plants are indistinguishable from apl lfy doubles. If both apl and lfy are inactive, it is irrelevant whether or not $C A L$ is present to boost their activity.

It may be that the role of $C A L$ is fully encompassed by $A P 1$, since cal- 1 reveals a phenotype only in an apl mutant background. The enhancement of the phenotype of weaker apl alleles by cal-1 such that they now resemble stronger apl alleles suggests that $C A L$ acts truly redundantly with $A P 1$ and that the strong apl-1 cal-1 phenotype is the consequence of none of the APl targets being activated. Even though they act redundantly, $C A L$ can substitute for only a proportion of $A P 1$ functions. If it could replace them all, the apl $C A L$ phenotype would be wild type.

Mutants with phenotypes closely similar to that of ap 1-1 cal-1 have been seen in other species. Most familiar is that of Brassica oleracea var botrytis, the cultivated cauliflower of our meal table (Sadik, 1962). In the same family as Ara bidopsis, the origin of its abnormal phenotype is apparently different. Its genetic basis depends upon one semi-dominant mutation rather than a combination of two mutations. The flowers that may break out of the inflorescence of cultivated cauliflowers are wild type and not apl-like (Yarnell, 1956). The anantha mutant of tomato also results in the proliferation of undifferentiated inflorescence primordia, but in this case a single recessive gene is responsible (Helm, 1951). Thus it seems a range of different genetic alterations can independently lead to the threshold conferring floral identity not being reached.

\section{Hyper-induction in terminal flower mutants}

Several lines of evidence suggest that the $t f$ mutant phenotype arises because such plants are 'over-induced' to flower. Firstly, $t f l$ plants are early flowering as compared to wild type (Shannon and Meeks-Wagner, 1991). Secondly, the number of normal flowers produced before the apical inflorescence meristem terminates in a floral meristem is influenced by environmental conditions (Shannon and Meeks-Wagner, 1991; Alvarez et al., 1992). The same noninductive environmental conditions that enhance the phenotypes of apl and lfy mutants, short days and low temperatures, reduce the severity of the $t f$ phenotype. Thirdly, $t f l-2$ ap $1-1$ cal-1 triple mutants look just like t $f-2$ ap $1-1$ doubles. That is, loss or reduction of $C A L$ activity has no effect in $t f l$ 2 ap 1-1 plants. This suggests that factors responsible for floral induction are already at high enough levels in tfl apl mutant plants such that $L F Y$ expression reaches levels sufficient to determine floral meristem identity without the stimulus provided by $C A L$. Fourthly, in $t f l-2$ plants, both AP1 (Fig. 5G-J) and LFY (Weigel et al., 1992) are ectopically expressed in the transformed terminal meristems. That is, these genes are activated in inappropriate parts of the inflorescence meristem perhaps in response to the very high levels of floral induction factors in $t f$ plants. Finally, terminal flowers can be produced by the normally indeterminate inflorescence meristem in Sinapis alba, another member of the Brassicaceae, if plants are given extreme inductive growth conditions (Bernier, 1992).

Double mutant combinations of $t f$ and apl (Results; Shannon and Meeks-Wagner, 1991) and of $t f$ and $l f y$ (D. W. and J. A., unpublished results) are apparently close to additive, suggesting that the TFL gene product does not interact directly with either of these main players. It may be that the normal TFL function is to inhibit one or several factors that promote floral induction (Koornneef et al., 1991) and that all the effects of $t f l$ mutations are direct or indirect consequences of this release from inhibition. Of course, it is possible that TFL function may negatively regulate $A P 1$ and $L F Y$ more directly in the apex of the inflorescence meristem. In the absence of TFL function, $A P I$ and $L F Y$ would now have the potential to become activated ectopically in these apices.

\section{The early role of APETALA2}

$A P 2$ also appears to have a role in the specification of floral meristem identity in addition to its later role in the specification of floral organ identity (see below). This seems likely even though flowers of ap2 single mutants reveal few if any inflorescence-like properties (Bowman et al., 1989; 1991). The evidence comes from double mutants involving ap2 alleles and either apl or lfy mutations. In each case, the flowers have enhanced inflorescence properties suggesting that the AP2 product positively interacts with both AP1 and LFY (Fig. 10). For example, combination of the strong ap22 mutant with the strong ap 1-1 mutant produces a larger number of flower-to-inflorescence conversions (second order inflorescences, Table 6). If the weak ap2-1 allele is involved with apl-1, the flowers produced are much more branched than in either single mutant (Table 6; Irish and Sussex, 1990). [The fact that there is much less branching in flowers of the ap1-1 ap2-2 double (Table 6) may result from ectopic expression of AGAMOUS (see below).] ap2 mutants also interact with lfy mutants in a parallel manner (Huala and Sussex, 1992). Similar intensified changes have been observed by us in weak ap2-1 lfy-5 doubles (unpublished).

These effects can be accounted for if, in the absence of either AP1 or LFY activity, AP2 activity is now required for the floral identity threshold to be reached in primordia developing on the flanks of the inflorescence apex (Fig. 10).

\section{Later roles of $A P 1$ in floral organ development}

Recent models of Arabidopsis flower development propose that the identities of the four whorls of floral organs are specified by the products of at least four floral homeotic genes APETALA2, APETALA3, PISTILLATA and AGAMOUS (Fig. 10; Bowman et al., 1991). The genes are suggested to function alone and in combination in three overlapping fields. Field A (whorls 1 and 2) is represented by $A P 2$, field $\mathrm{B}$ (whorls 2 and 3 ) is represented by $A P 3$ and $P I$, and field $\mathrm{C}$ (whorls 3 and 4 ) is represented by $A G$. In addition, it is proposed that the $\mathrm{A}$ and $\mathrm{C}$ functions are mutually antagonistic (Bowman et al., 1991; Fig. 10).

Mandel et al. (1992) found that, from late stage 3, AP1 is expressed in regions of flower primordia corresponding to field $\mathrm{A}$ and proposed that $A P l$ is involved in determining development of the outer two whorls. Observations on our 
allelic series of apl mutants support this, as disruption is predominantly confined to sepal and petal development. It seems likely that $A P 1$ promotes or acts as a partner in the activity of $A P 2$, the other known field A gene, in specifying the identity of outer whorl organs (Fig. 10). This is because double mutant combinations involving weak alleles, such as ap1-5 ap2-1, exhibit a much enhanced change in organ identity toward that of strong ap 2 mutant alleles (Fig. 8E).

Mandel et al. (1992) also suggested that APl expression may be negatively regulated by $A G$ in whorls 3 and 4 (Fig. $10)$. This was proposed because $A P 1$ is not normally expressed in the inner whorls once $A G$ comes on, but it is if $a g$ is in mutant form. Further, this negative regulation of $A P 1$ by $A G$ may extend to the outer two whorls in ap2 mutants where $A G$ is ectopically expressed in whorls one and two (Drews et al., 1991). Consistent with this, strong ap2 alleles are epistatic to strong and weak apl alleles with respect to disruptions to the identity of floral organs (Fig. 8B).

Proposed interactions between $A P 1, A P 2$ and $A G$ from stage 3 can be summarized thus: $A P 2$ negatively regulates $A G$ in field A, $A G$ negatively regulates $A P l$ in field $\mathrm{C}$, and both $A P 1$ and $A P 2$ are necessary for A function (Fig. 10). Mutant phenotypes of the outer whorl organs can be accounted for as follows. In ap 2 mutants, $A G$ comes on and inactivates $A P 1$ in field A leading to carpelloid first whorl organs. By contrast, in apl mutants expression of $A P 2$ and $A G$ is largely normal but A function is disrupted resulting in bract-like organs developing in place of sepals. In $a g$ mutants $A P 1$ and $A P 2$ act as usual in field $\mathrm{A}$ and the outer whorl organs are normal sepals. However, these genes are also ectopically active in field $\mathrm{C}$ and stamen to petal conversion is one result. $A P l$ thus appears to be, along with $A P 2$, a component of the A function that regulates organ identity in whorls one and two. This follows both from its action in specifying organ identity in these whorls, and from the regulatory interaction between $A P 1$ and the $\mathrm{C}$ function gene $A G$.

One effect of apl mutations may be an ectopic expansion of field $\mathrm{C}$ activity into areas of the flower primordium where field A function is now compromised. This could account for why stamens sometimes arise in positions normally occupied by second whorl organs and why second whorl organs themselves do not develop. The latter could be related to ectopic $A G$ expression and the role that $A G$ normally plays in suppressing growth in the center of the determinant flower primordium (Bowman et al., 1991). Consistent with this, petals may reappear in second whorl positions of apl flowers when $A G$ is also inactivated (as in apl ag doubles (Fig. 8K,L)). Finally, petal-stamen mosaic organs seen in the second whorl of apl mutants (Fig. 3G,H) could develop from primordia that straddle the $\mathrm{A} / \mathrm{C}$ boundary.

\section{The phenotype of ap1 ap2 ag triple mutants}

An observation that needs to be accounted for is the inability of 'floral' meristems in ap 1-1 ap2-2 ag-1 triple mutants to develop mature organs of any type. Indeed, such meristems seem to revert frequently to inflorescence-like meristems. This is perhaps unexpected given that the two earlier acting genes which control flower meristem identity, $A P 1$ and $A P 2$, do not lead to such a phenotype when in double mutant combination. The additional inactivation of the later acting $A G$ seems to be responsible.

It seems that, in the triple apl ap2 ag mutant, the ectopic flower that normally develops inside an $\mathrm{ag}$ flower frequently loses its floral identity and reverts back to inflorescence-like growth. When a primordium first develops on the flank of the triply mutant inflorescence meristem, sufficient activities of those factors that specify floral meristem identity are apparently present to allow it take on floral identity and to develop first whorl primordia (stage 3). However, perhaps these activities fall away in the central cells of the flower primordium and they revert to inflorescence-like growth. A similar explanation might apply in ap $1-1$ ag-1 double mutants where we found that many flowers also revert to inflorescence growth patterns. The fact that loss of $A G$ seems to be responsible for the dramatic reversionary phenotype of the triple mutant suggests that $A G$ plays a role in maintaining floral identity. Additional evidence for this role is that in ag single mutants secondary flowers occasionally arise in the axils of the sepals and such flowers are more common in ag ap2 double mutants (unpublished observations).

\section{AP1 function in Arabidopsis resembles SQUA function in Antirrhinum}

APl has a cognate homolog in Antirrhinum majus, the SQUAMOSA gene (Huijser et al., 1992). API and SQUA share $68 \%$ identity in their predicted amino acid sequence and their patterns of expression in flower development are closely similar (Mandel et al., 1992). The corresponding mutant phenotypes also share some features. There is an incomplete conversion of flower meristems into inflorescence meristems in squa mutants, even in null mutants (Huijser et al., 1992). The range of floral organ types in squa mutant plants is also somewhat similar to that in apl mutants (Huijser et al., 1992).

Flower development in squamosa mutants is also environmentally sensitive so it is difficult to compare directly the relative severity of squa and apl mutational effects. However, the phenotypes reported by Huijser et al. (1992) reflect more frequent and more complete conversions of floral meristems to inflorescence meristems. Conversely, if flowers arise in squa plants, they usually seem to be less severely affected than in apl. These differences indicate that AP1 plays a less important role than SQUA early in establishing floral meristem identity, but a more important role later in the developing flower.

It seems likely that a core of conserved regulatory genes underpin the control of floral development across flowering plants. Even though such genes seem to have retained their basic roles, modification of their expression patterns and their interactions may account for at least some of the great diversity in inflorescence and flower structure that has arisen since flowering plants first appeared.

Special thanks go to Marty Yanofsky for making the APl probe available prior to publication and for constructive comments on the manuscript. We also thank Tom Jack, Gerd Bossinger, Megan Griffith and Alan Neale for helpful discussion of the manuscript. We are indebted to Maarten Koornneef and Luca Comai for supplying genetic material. Gunta Jaudzems provided excellent 
microscopy facilities. J. L. B. was supported by a Short Term Fellowship from the Human Frontiers Science Program and an Australian Research Council Postdoctoral Research Fellowship. J. A. held a Monash Postgraduate Scholarship. D. W. was supported by a EMBO Long Term Fellowship and a Senior Fellowship from the American Cancer Society, California Division. This work was supported by an Australian Research Council Grant A19131181 to D. R. S. and a US Department of Energy, Division of Energy Biosciences Grant DE-FG03-88ER13873 and a US National Science Foundation Grant MCB-9204839 to E. M. M.

\section{REFERENCES}

Alvarez, J., Guli, C. L., Yu, X.-H. and Smyth, D. R. (1992). terminal flower: a gene affecting inflorescence development in Arabidopsis thaliana. Plant J. 2, 103-116.

Bernier, G. (1992). Attempts to bridge the molecular genetics and physiology of inflorescence and flower mophogenesis. Flowering Newsletter 14, 34-40.

Bowman, J. L., Smyth, D. R. and Meyerowitz, E. M. (1989). Genes directing flower development in Arabidopsis. Plant Cell 1, 37-52.

Bowman, J. L., Smyth, D. R. and Meyerowitz, E. M. (1991). Genetic interactions among floral homeotic genes of Arabidopsis. Development 112, $1-20$.

Carpenter, R. and Coen, E. S. (1990). Floral homeotic mutations produced by transposon-mutagenesis in Antirrhinum majus. Genes Dev. 4, 14831493.

Coen, E. S. and Meyerowitz, E. M. (1991). The war of the whorls: genetic interactions controlling flower development. Nature 353, 31-37.

Coen, E. S., Romero, J. M., Doyle, S., Elliott, R., Murphy, G. and Carpenter, R. (1990). floricaula: a homeotic gene required for flower development in Antirrhinum majus. Cell 63, 1311-1322.

Drews, G. N., Bowman, J. L. and Meyerowitz, E. M. (1991). Negative regulation of the Arabidopsis homeotic gene AGAMOUS by the APETALA2 product. Cell $\mathbf{6 5}, 991-1002$.

Feldmann, K. A. and Marks, M. D. (1987). Agrobacterium-mediated transformation of germinating seeds of Arabidopsis thaliana: a non-tissue culture approach. Mol. Gen. Genet. 208, 1-9.

Helm, J. (1951). Vergleichende Betrachtungen über die Entwicklung der Infloreszenz bei Lycopersicum esculentum Mill. und bei einer Röntgenmutante. Züchter 21, 89-95.

Hill, J. P. and Lord, E. M. (1989). Floral development in Arabidopsis thaliana: a comparison of the wildtype and the homeotic pistillata mutant. Can. J. Bot. 67, 2922-2936.

Huala, E. and Sussex, I. M. (1992). LEAFY interacts with floral homeotic genes to regulate Arabidopsis floral development. Plant Cell 4, 901913.

Huijser, P., Klein, J., Lönnig, W.-E., Meijer, H., Saedler, H. and Sommer, H. (1992). Bracteomania, an inflorescence anomaly, is caused by the loss of function of the MADS box gene squamosa in Antirrhinum majus. EMBO J. 11, 1239-1249.
Irish, V. F. and Sussex, I. M. (1990). Function of the apetalal-1 gene during Arabidopsis floral development. Plant Cell 2, 741-753.

Koornneef, M., Hanhart, C. J. and van der Veen, J. H. (1991). A genetic and physiological analysis of late flowering mutants in Arabidopsis thaliana. Mol. Gen. Genet. 229, 57-66.

Ma, H., Yanofsky, M. F., Meyerowitz, E. M. (1991). AGL1-AGL6, an Arabidopsis gene family with similarity to floral homeotic and transcription factor genes. Genes Dev. 5, 484-495.

Mandel, M. A., Gustafson-Brown, C., Savidge, B. and Yanofsky, M. F. (1992). Molecular characterization of the Arabidopsis floral homeotic gene APETALA1. Nature 360, 273-277.

Müller, A. (1961). Zur Charakterisierung der Blüten und Infloreszenzen von Arabidopsis thaliana (L.) Heynh. Kulturpflanze 9, 364-393.

Napp-Zinn, K. (1985). Arabidopsis thaliana. In CRC Handbook of Flowering vol. 1. (ed. A. H. Halevy), pp. 492-503. Boca Raton: CRC Press.

Sadik, S. (1962). Morphology of the curd of cauliflower. Amer. J. Bot. 49, 290-297.

Schultz, E. A. and Haughn, G. W. (1991). LEAFY, a homeotic gene that regulates inflorescence development in Arabidopsis. Plant Cell 3, 771781.

Schwarz-Sommer, Z., Huijser, P., Nacken, W., Saedler, H. and Sommer, H. (1990). Genetic control of flower development: homeotic genes of Antirrhinum majus. Science 250, 931-936.

Shannon, S. and Meeks-Wagner, D. R. (1991). A mutation in the Arabidopsis TFL1 gene affects inflorescence meristem development. Plant Cell 3, 877-892.

Smyth, D. R., Bowman, J. L. and Meyerowitz, E. M. (1990). Early flower development in Arabidopsis. Plant Cell 2, 755-767.

Weigel, D., Alvarez, J., Smyth, D. R., Yanofsky, M. F. and Meyerowitz, E. M. (1992). LEAFY controls floral meristem identity in Arabidopsis. Cell 69, 843-859.

Weigel, D. and Meyerowitz, E. M. (1993) Genetic hierarchy controlling flower development. In Molecular Basis of Morphogenesis (ed. M. Bernfield). 51st Annual Symposium of the Society for Developmental Biology New York: Wiley. (In press)

Yarnell, S. H. (1956). Cytogenetics of the Vegetable Crops. II. Crucifers. The Bot. Rev. 22, 81-166.

Yanofsky, M. F., Ma, H., Bowman, J. L., Drews, G. N., Feldmann, K. A. and Meyerowitz, E. M. (1990). The protein encoded by the Arabidopsis homeotic gene agamous resembles transcription factors. Nature 346, 35 40.

(Accepted 26 July 1993)

\section{Note added in proof}

While this manuscript was under review, a related study appeared reporting mutant combinations of apetalal with terminal flower, leafy and apetala 2 mutants (Shannon, S. and Meeks-Wagner, D. R. (1993). Genetic interactions that regulate inflorescence development in Arabidopsis. Plant Cell 5, 639-655.). 